\title{
Fighting for votes: theory and evidence on the causes
}

\author{
of electoral violence.*
}

\author{
Olivier Sterck ${ }^{\dagger}$
}

June 2019

\begin{abstract}
I develop a theory of pre-electoral violence, in which parties resort to violent tactics if political competition is tight and violent supporters are numerous, and if polarization between violent supporters is high. The importance of these conditions varies with the type of violence (clashes, intimidation or murders). I test the model using data on the 2010 elections in Burundi. In line with the model, electoral violence before the election was more likely in municipalities characterized by both close political competition and high density of demobilized combatants. Violence was also more likely where polarization between demobilized combatants was high.

Keywords: Electoral violence, Polarization, Fractionalization, Political competition, Burundi
\end{abstract}

JEL Classification: D74, D72, O12, O55

*I thank the 4 anonymous referees and the editor of Economica, Stéphane Baele, Paul Collier, Andrea Colombo, Olivia D'Aoust, Jean-Benoit Falisse, James Fenske, Remco Geervliet, Eliana La Ferrara, Claire MacPherson, Mthuli Ncube, Nathan Nunn, Simon Quinn, Philip Verwimp and participants at the CSAE and QEH research workshops (University of Oxford), 3rd DIAL Conference (University of Paris-Dauphine), the NCDE conference (University of Copenhagen), the Burundi Symposium (Ghent University) for helpful comments and discussions. This paper is a companion paper to Colombo et al. (2019).

†Correspondence: University of Oxford, Oxford Department of International Development (ODID), Mansfield road 3, OX1 3TB, United Kingdom, Phone: +44 7826677 594, Email: olivier.sterck@qeh.ox.ac.uk. 


\section{Introduction}

"Democratic institutions and processes channel competing interests into arenas of discourse and provide means of compromise which can be respected by all participants in debates, thereby minimizing the risk that differences or disputes will erupt into armed conflict or confrontation."

Former U.N. Secretary-General Boutros Boutros-Ghali (1996)

Democratization has been widely promoted in developing countries since the end of the Cold War. As exemplified by Boutros-Ghali's quote, the prevailing idea has been that by increasing the legitimacy and the accountability of elected representatives, elections would de facto improve governance and thereby reduce the risk of conflict. Yet in spite of these expectations, a majority of elections organized in recent democracies have been marked by violence or fraud (Bishop and Hoeffler 2014). Election violence - but also the fear of violence - can affect voter turnout, election results as well as parties' political agendas (Getmansky and Zeitzoff 2014; Gould and Klor 2010; Ellman and Wantchekon 2000). When poorly conducted, elections fail to discipline leaders, thereby undermining governance and economic policies (Collier and Hoeffler 2015; Chauvet and Collier 2009). Besides direct casualties, election violence can have dramatic consequences on civilian populations, reducing income, expenditures and consumption (Dupas and Robinson 2012, 2010), and triggering mass-movements of civilians fleeing violence (Steele 2011). In order to prevent election violence and its dramatic effects on welfare and policy, understanding when and where violence occurs is essential. This is the objective of this paper.

Different actors with different motives can use illicit or violent strategies at different stages of the electoral process (Matanock and Staniland 2018; Mares and Young 2016). Before election day, candidates and parties, often in conjunction with mafias (De Luca and De Feo 2017), militias (Acemoglu et al. 2013), or gangs (Dercon and Gutiérrez-Romero 2012), may engage in intimidation or violence to gain an electoral advantage. On election day, insurgents and other groups excluded from the democratic process may increase their attacks to undermine the rule and legitimacy of the prevailing power structures 
(Condra et al. 2017). After the elections, losing parties may challenge election results and coordinate protests or rebellion (Fearon 2011), which, in turn, can be severely quashed by the government (Hafner-Burton et al. 2016; Bhasin and Gandhi 2013). Violent actors can also retaliate against people or localities who voted in a certain way.

In this paper, I study theoretically and empirically the causal dynamics of pre-electoral violence, exploring why and where political parties use violent tactics before elections to gain an electoral advantage. I proceed in two steps.

I propose a theoretical model of pre-electoral violence, ${ }^{1}$ which extends the pioneering model of Skaperdas and Grofman (1995), Chaturvedi (2005), and Collier and Vicente (2012) by formalizing the relationship between violence and the distribution of voters and violent supporters, as measured by fractionalization and polarization indicators (Esteban and Ray 2011; Esteban et al. 2012b). The new model is inspired by the empirical work of Colombo et al. (2019), which is a companion paper to the present article, ${ }^{2}$ and by the theoretical model of Chacón et al. (2011) on the consolidation of democracy. ${ }^{3}$

In the new theoretical framework, electoral competition takes the form of a contest between two parties to get a benefit $B$. The game is sequential. Parties first decide whether to participate in the electoral campaign. Parties then choose whether or not they engage in electoral violence to gain a supplementary share of votes, or deter opponents from voting. However, engaging in electoral violence is costly and the outcome of violence is uncertain: the likelihood that a violent move is successful depends on the initial capacity

\footnotetext{
${ }^{1}$ An analysis of post-electoral violence would require a different model, as violence after the election might be related to protests, repression, retaliation, or frustration (see e.g. Hafner-Burton et al. (2016) and Daxecker (2012)).

${ }^{2}$ Colombo et al. (2019) find that polarization between ex-rebel groups and tight political competition are the best predictors of electoral violence in the context of the 2010 elections in Burundi. The present paper extends the work of Colombo et al. (2019) by proposing a theoretical model of pre-electoral violence. A new indicator of polarization is derived theoretically and compared to the polarization index of Garcia-Montalvo and Reynal-Querol (2005b) (the measure is used in Colombo et al. (2019)). In line with the theoretical model, and in contrast with Colombo et al. (2019), the empirical analysis of the present paper focuses on pre-electoral violence, distinguishing different types of electoral misconducts. The present paper studies in details the interaction effects between political competition and the presence of ex-combatants.

${ }^{3}$ Chacón et al. (2011) show that democracy might not be stable when the support of the parties is evenly balanced, because parties then have an incentive to fight. I extend this work by focusing preelectoral violence, by studying the impact of the distribution of violent supporters, and by distinguishing different types of violent events.
} 
of parties to engage in violence and on the type of violence. The violent capacity of parties is modeled as their number of violent supporters. The model introduces the distinction between unilateral and bilateral acts of violence. On the one hand, one party alone can decide to engage in unilateral violence against its rival (e.g. murder of an opponent). In this case, the probability that a violent move is successful depends only on the violent capacity of the violent party, that is, on its own number of violent supporters. On the other hand, bilateral violence occurs when both parties engage in violent campaigning (e.g. clashes between rival parties). In this case, only one of the parties is successful and the probability that a party wins the violent contest increases with its violent capacity and decreases with the violent capacity of the rival.

The new model offers original predictions. Electoral violence is more likely to emerge if two conditions are jointly satisfied. First, political competition should be tight and the number of violent supporters involved should be large, such that violent parties expect to win the election if their violent move is successful. Second, parties only engage in violence if the likelihood of success is sufficiently high. A key implication is that bilateral violence is more likely to emerge if parties have similar violent capacities, such that both parties have a reasonable chance of winning the violent contest. Bilateral violence is unlikely between parties with very different violent capacities. This important and counter-intuitive finding follows from the two-stage structure of electoral competition: weak parties refrain from campaigning if they fear the harmful consequences of violent acts carried out by a much stronger rival party. Therefore, a necessary condition for the occurrence of electoral violence is that rival parties should be characterized by similar violent capacities. This condition is equivalent to requiring that polarization between violent supporters should be high. ${ }^{4}$ For unilateral violence, the relationship between electoral violence and polarization between violent supporters is more tenuous, and this relationship weakens with the cost of violence. These predictions contrast with the conclusions of existing models, which predict that violence incidence is the highest in the presence of a party which is electorally weak,

\footnotetext{
${ }^{4}$ Following Garcia-Montalvo and Reynal-Querol (2005b), polarization captures how far the distribution of groups is from a bipolar distribution.
} 
but which is strong in terms of violent capacity (Collier and Vicente 2012; Chaturvedi 2005; Skaperdas and Grofman 1995).

An important by-product of the model is a new indicator of polarization, which is derived theoretically and compared to the polarization index of Garcia-Montalvo and Reynal-Querol (2005b).

I test the new theoretical predictions in the context of the 2010 Burundian electoral process. The 2010 Burundian elections are of particular interest as they were the first elections to be organized after a 16-year long civil conflict. ${ }^{5}$ Demobilized factions which were transformed into political parties at the end of the civil war were competing against parties of civilians in a context of widespread insecurity and extreme uncertainty about electoral outcomes. I use an extended dataset that combines data on electoral violence in Burundi from a companion paper (Colombo et al. 2019) with data on geographic characteristics from Henderson et al. (2018).

The empirical analysis examines whether pre-electoral violence at the municipal level is correlated with political competition, ${ }^{6}$ polarization between violent supporters, ${ }^{7}$ and various control variables including ethnic fractionalization. In line with the theoretical model, and in contrast with Colombo et al. (2019), I focus on pre-electoral violence, I distinguish different types of electoral misconducts, and I study in details the interaction effects between political competition and the presence of ex-combatants. I use geographical fixed effects to minimize the risk of omitted variable bias, relying on the assumption that neighboring municipalities are more likely to share similar unobserved characteristics.

In accordance with the model, political competition between parties is a key driver of electoral violence, especially where demobilized combatants are numerous. Violence is

\footnotetext{
${ }^{5}$ Elections were also organized in 2005 while a rebel group, the Palipehutu-FNL, was still fighting the government of transition.

${ }^{6}$ In line with Besley et al. (2010) the indicator of political competition measures if elections are contested. In the main specification, political competition is measured by fragmentation of the vote in previous elections.

${ }^{7}$ In the main specification, polarization between violent supporters is measured by an indicator of polarization between ex-combatants who have returned to a municipality.
} 
also more likely to emerge in places where polarization between ex-rebel groups is high, that is, where parties have a similar potential for violence. A one-standard-deviation increase in ex-rebels' polarization induces a $66-85 \%$ increase in the predicted number of violent episodes. The latter effect is especially strong for bilateral violence. These findings are relatively robust across a variety of specifications and tests, suggesting that omitted variables, spatial dependence, reverse causality, and specific functional forms do not significantly bias the results.

The paper is organized as follows. The new theoretical model is developed in Section 2. The context of the 2010 elections in Burundi is described in Section 3. The data and identification strategy are described in Section 4, and results are presented in Section 5. Section 6 shows that results are robust to a variety of specifications and robustness checks. By way of conclusion, Section 7 discusses the contributions of the paper, highlighting avenues for future research.

\section{Theoretical model}

\section{$2.1 \quad$ Set-up}

Two parties, denoted by subscripts 1 and 2, compete for elections. Winning the election brings a "payoff" $B$ to the winning party. This payoff is not restricted to monetary gains; it also includes non-monetary benefits such as political hegemony and prestige. The population is divided into three groups according to initial support for parties before the electoral campaign. A share $h_{1}$ of the population consists of violent supporters for party 1. A share $h_{2}$ of the population consists of violent supporters for party 2. The rest, a share $v_{u}$ of the population, is undecided and their voting choice depends on the campaign, with $h_{1}+h_{2}+v_{u}=1$. The game is sequential.

In the first stage, parties can engage in political campaigning to convince undecided voters to vote for them. If only one party engages in political campaigning, meaning that its rival does not compete in the elections, it gets all votes. If both parties engage in 
political campaigning, they obtain $v_{1}$ and $v_{2}$ votes respectively.

In the second stage, parties can engage in conflictual campaigning. Violent parties bear a fixed $\operatorname{cost} C$, which includes the cost of material and human resources ${ }^{8}$ as well as the expected cost of a possible sanction. ${ }^{9}$ This cost is assumed to be lower than the benefit from violence $(0<C<B)$.

To determine when a violent move is successful, two types of electoral misconducts are distinguished: bilateral and unilateral types of violence. ${ }^{10}$ The typical example of bilateral violence is a clash between parties. For bilateral violence to emerge, both parties should make a violent move. In this case, a conflictual contest occurs and the party $i$ has a probability $Q\left(h_{i}, h_{j}\right)$ of winning the contest, with $Q\left(h_{i}, h_{j}\right)=1-Q\left(h_{j}, h_{i}\right)$. In the case of a clash, it is intuitive to assume that the likelihood that the party $i$ wins a contest is increasing with its number of violent supporters and decreasing with the number of violent supporters of its rival. The model therefore assumes that $Q\left(h_{i}, h_{j}\right)$ is increasing in $h_{i}$ and decreasing in $h_{j}$.

Examples of unilateral violence include murders of opponents or intimidation. Unilateral violence occurs even if only one party makes a violent move. In the case of unilateral violence, the probability that the party $i$ succeeds in its violent move only depends on its own number of violent supporters. The sum of probabilities $q\left(h_{1}\right)+q\left(h_{2}\right)$ can differ from one.

The victim of a successful violent move - be it bilateral or unilateral - incurs damage cost $D$. This cost includes the cost of physical damage as well as the cost of humiliation and other psychological harm. A successful violent move also induces a transfer of votes from the victim to the violent party. This transfer of votes is assumed to be proportional

\footnotetext{
${ }^{8} \mathrm{C}$ therefore includes the cost of recruiting violent actors, e.g. demobilized combatants (Human Rights Watch 2010), mafias (De Luca and De Feo 2017), militias (Acemoglu et al. 2013), or gangs (Dercon and Gutiérrez-Romero 2012).

${ }^{9} \mathrm{C}$ is therefore expected to be relatively low when institutions are weak, and when the likelihood of arrest and prosecution is low. In contrast, $C$ will be high in the presence of strong institutions, in which case violence is never an optimal strategy.

${ }^{10}$ Given the nature of the theoretical exercise, a clear distinction is made between the two categories of violence to identify unambiguous theoretical mechanisms. In practice, the boundaries between the two categories may be more or less fuzzy, and some violent events may fall into both categories.
} 
to the total number of violent supporters engaging in violence. While a minor fight between a few violent supporters is unlikely to have a big effect, a massive clash between numerous rival supporters is likely to exacerbate fears and strategic voting. Similarly, intimidation is expected to have a greater impact when it is performed by numerous supporters. I therefore assume a transfer of $\delta\left(h_{1}+h_{2}\right)$ votes from the victim to the perpetrator of violence. ${ }^{11}$ The same results are obtained with the alternative assumption that $2 \delta\left(h_{1}+h_{2}\right)$ voters of the rival party are deterred from voting. ${ }^{12}$

In the next sections, the dynamic game is solved by backward induction, separately for bilateral and unilateral violence.

\subsection{Bilateral violence}

In the second stage of the game, parties determine whether to engage in violent campaigning or not. Parties will only perpetrate violence if it is decisive for winning the elections. In other words, party $i$ will only engage in bilateral violence if winning the violent contest would provide enough votes to win the elections $\left(v_{i}+\delta\left(h_{i}+h_{j}\right)>0.5\right)$ and if it needs violence to win the elections if the other party is violent $\left(v_{i}-\delta\left(h_{i}+h_{j}\right)<0.5\right)$. These conditions should be satisfied for both parties. The following condition is therefore necessary for bilateral violence to emerge:

$$
\left|v_{1}-v_{2}\right|<2 \delta\left(h_{1}+h_{2}\right) \text {. }
$$

Condition (1) states that the election should be close. If condition (1) is not satisfied, parties do not resort to violence as it cannot change the outcome of the election.

If condition (1) is satisfied, the dynamic game is represented in Figure 1. Without loss

\footnotetext{
${ }^{11}$ If only one party wants to have a fight while the other party refrains from it, the violent party also gains a share $\delta\left(h_{1}+h_{2}\right)$ of votes.

${ }^{12}$ For example, with this alternative assumption, the party $i$ will only engage in bilateral violence if winning the violent contest leads to an electoral victory (i.e. if $v_{i}>v_{j}-2 \delta\left(h_{i}+h_{j}\right)$ ) and if losing the violent contest leads to an electoral defeat $\left(v_{i}-2 \delta\left(h_{i}+h_{j}\right)<v_{j}\right)$. These conditions should be satisfied for both parties. Solving these equations leads to equation (1).
} 
of generality, we assume that party 1 gets more votes if no party engage in violent campaigning $\left(v_{1}>v_{2}\right)$. This game is quite straightforward to solve by backward induction. In the second stage, party 2 resorts to violence if party 1 opts for political campaigning without violence. By contrast, party 1 does not need violence if party 2 remains peaceful. Therefore, only two Nash Equilibria are possible in the second stage: party 2 alone using violence, or the two parties fighting in a violent contest. These two Nash Equilibria are mutually exclusive. In the first stage, the outcomes of the Nash equilibrium of the second stage are compared to the payoffs from not actively participating to the political campaign, i.e. 0 .

The violent equilibrium Violence is a dominant strategy for player 2 in the two stages if $B Q\left(h_{2}, h_{1}\right)-C-D Q\left(h_{1}, h_{2}\right)>0$. Party 1 reacts by also engaging in violence if $B Q\left(h_{1}, h_{2}\right)-C-D Q\left(h_{2}, h_{1}\right)>0$. Because $Q\left(h_{1}, h_{2}\right)=1-Q\left(h_{2}, h_{1}\right)$, these conditions can be rewritten:

$$
\frac{C+D}{B+D}<Q\left(h_{1}, h_{2}\right)<1-\frac{C+D}{B+D}
$$

Bilateral violence is therefore the unique sub-game perfect Nash equilibrium of the game if conditions (1) and (2) are jointly satisfied.

Proposition 1. Electoral violence is the unique sub-game perfect Nash Equilibrium if political competition and competition between violent supporters are high such that the following two conditions are satisfied:

$$
\left\{\begin{array}{l}
\left|v_{1}-v_{2}\right|<2 \delta\left(h_{1}+h_{2}\right) \\
\frac{C+D}{B+D}<Q\left(h_{1}, h_{2}\right)<1-\frac{C+D}{B+D} .
\end{array}\right.
$$

If these conditions are satisfied, engaging in violence is a dominant strategy for the electorally weakest party.

Proof. The proof is in the text. 


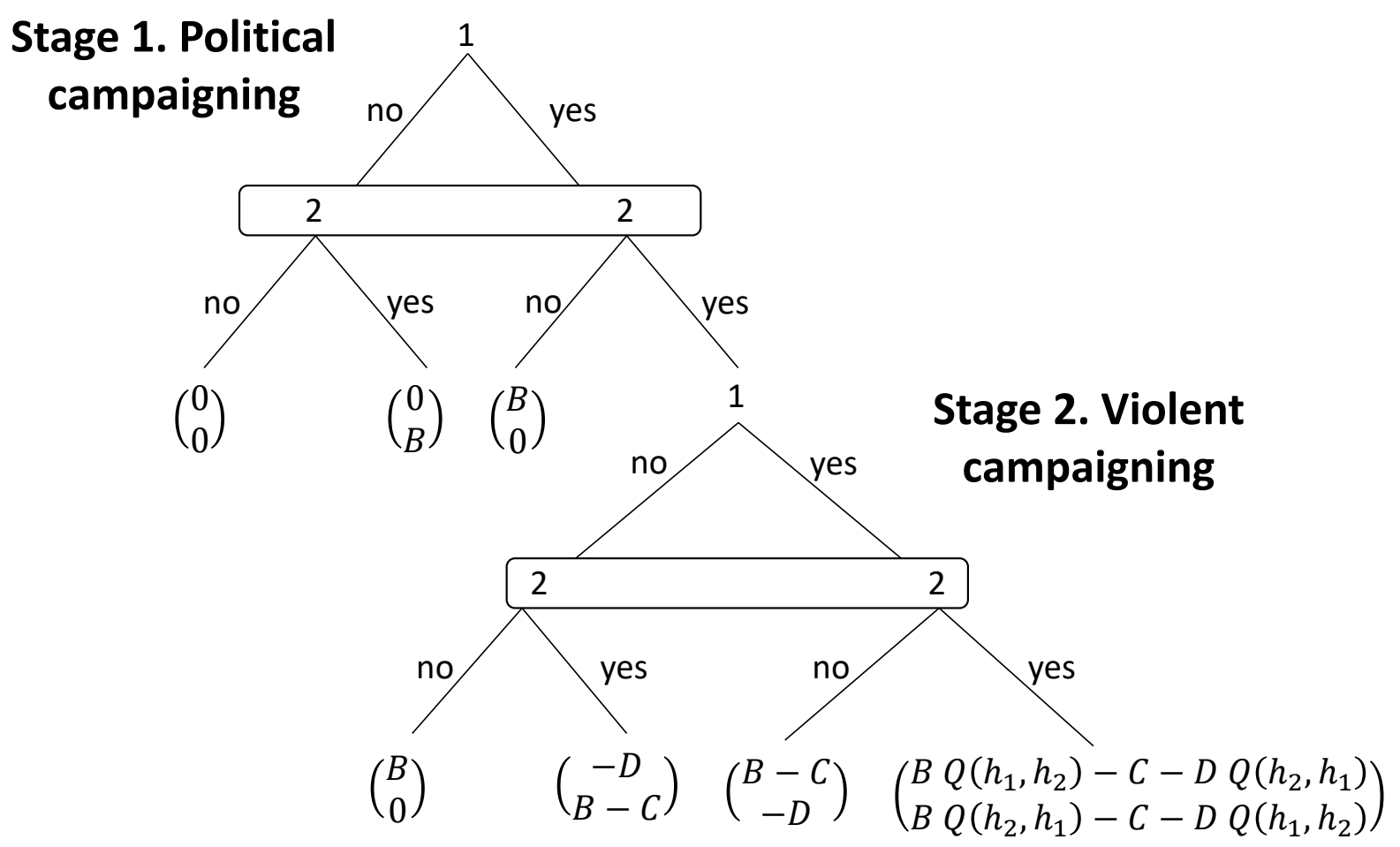

Figure 1 - Bilateral violence - pay-offs of the dynamic game.

The first condition states that each group expects to win the election if it wins the conflictual contest. Indeed, it only makes sense to engage in violence if it can bring about the victory. This should be true for both parties. As illustrated in Figure 2(a), this condition is satisfied if the election is close and if the expected voting gain after a successful violent move, $\delta\left(h_{1}+h_{2}\right)$, is high. Tight political competition and a high number of violent supporters are expected to be complementary factors of violence.

The second condition states that the probability that party 1 wins the violent contest should be intermediate for bilateral violence to emerge. As $Q\left(h_{1}, h_{2}\right)=1-Q\left(h_{2}, h_{1}\right)$, the same should be true for the probability that the party 2 wins. As the probability that a given party wins a contest is increasing in its own number of violent supporters and decreasing in the rival's number of violent supporters, bilateral violence only emerges if both parties have a similar number of violent supporters. This key prediction follows from the two-stage structure of electoral competition and from the assumptions that violence is costly both for perpetrators and for victims of violence. As a result, parties refrain 
from campaigning if they fear the harmful consequences of violent acts made by a much stronger party.

This equilibrium is illustrated in Figure 2(b). The probability $Q\left(h_{i}, h_{j}\right)$ is modeled as a Tullock contest success function: $Q\left(h_{i}, h_{j}\right)=h_{i} /\left(h_{i}+h_{j}\right)$. Bilateral violence emerges if both parties have a similar number of violent supporters, implying that they both have a reasonable chance to win the violent contest. Said differently, Figure 2(b) shows that bilateral violence emerges only if polarization between violent supporters is high.

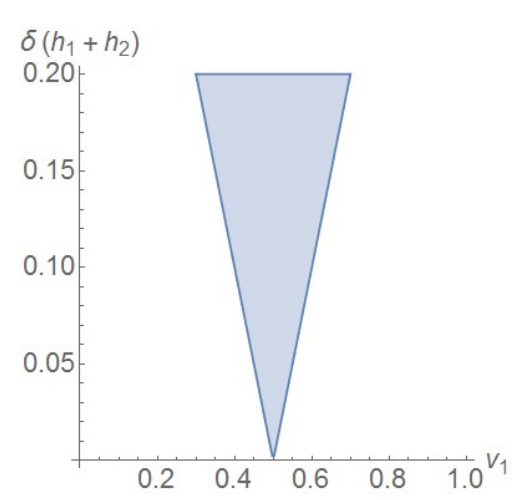

(a) Condition (1)

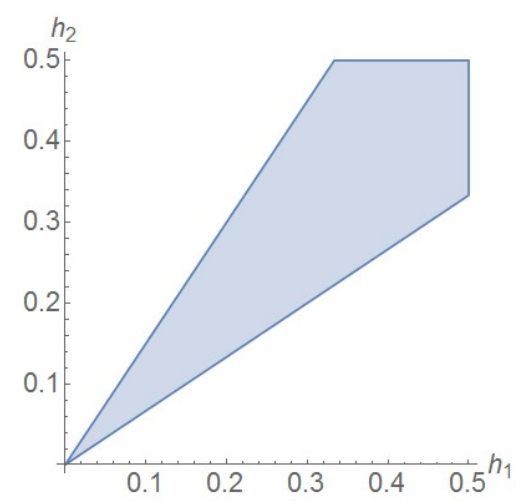

(b) Condition (2)

Figure 2 - Bilateral violence $(\mathrm{B}=100, \mathrm{C}=25, \mathrm{D}=25)$. The blue plain area depicts combinations of $\delta, v_{1}, h_{1}$ and $h_{2}$ such that both parties engage in violence.

The non-violent equilibria Four different peaceful equilibria are possible. These equilibria are represented in Figures 3(a) to 3(d) for different parameter values, with $Q\left(h_{i}, h_{j}\right)$ modeled as a Tullock contest success function.

First, party 2 does not engage in political campaigning in the first stage to avoid the violent Nash Equilibrium in the second stage if its number of violent supporters is too low compared to party 1 such that the expected benefit of a violent contest is below zero (Red area, labeled B). This equilibrium occurs if $\max \left(\frac{B-C}{B+D}, \frac{C}{B+D}\right)<Q\left(h_{1}, h_{2}\right)<1-\frac{C}{B+D}$. Second, party 1 does not participate in political campaigning in the first stage if its chances of winning the violent contest in the second stage are too low (Green area, labeled D). This peaceful equilibrium takes place if $\frac{C}{B+D}<Q\left(h_{1}, h_{2}\right)<\min \left(\frac{B-C}{B+D}, \frac{C+D}{B+D}\right)$. Third, if the number of violent supporters of party 2 is much larger the number of violent 
supporters of party 1, the Nash Equilibrium in the second stage is given by party 1 remaining peaceful while party 2 resorts to violence. This equilibrium is suboptimal for party 1 , which prefers not to actively participate in the political campaign in the first stage (Yellow area, labeled E). This equilibrium occurs if $Q\left(h_{1}, h_{2}\right)<\frac{C}{B+D}$. Finally, if the number of violent supporters of party 1 is much larger than the number of violent supporters of party 2, there will be no Nash Equilibrium in pure strategies in the second stage. In this case, party 2 always remains peaceful because it knows that party 1 would respond to violence with violence, which would be suboptimal for party 2 (Purple area, labeled C). This equilibrium occurs if $Q\left(h_{1}, h_{2}\right)>\max \left(\frac{C}{B+D}, 1-\frac{C}{B+D}\right)$.

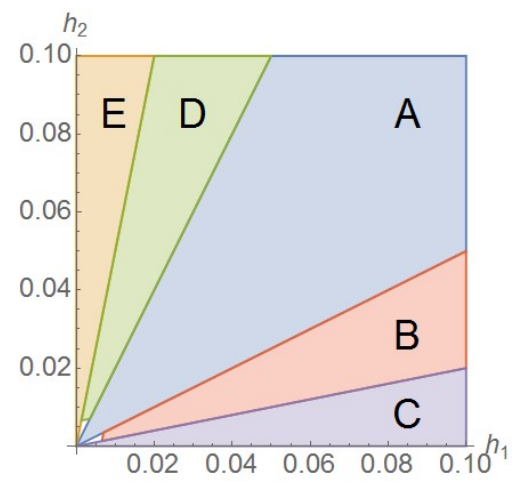

(a) $\mathrm{B}=100, \mathrm{C}=20, \mathrm{D}=20$

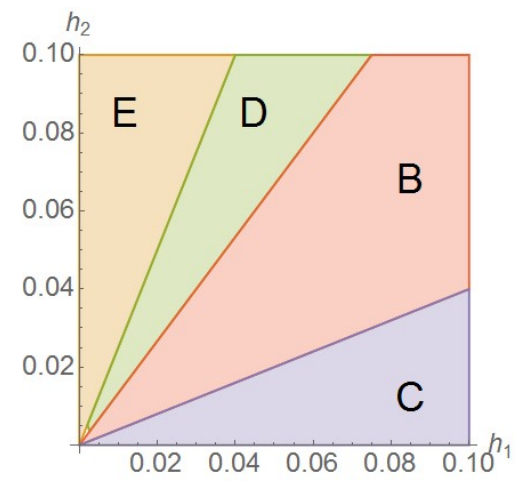

(c) $\mathrm{B}=100, \mathrm{C}=40, \mathrm{D}=40$

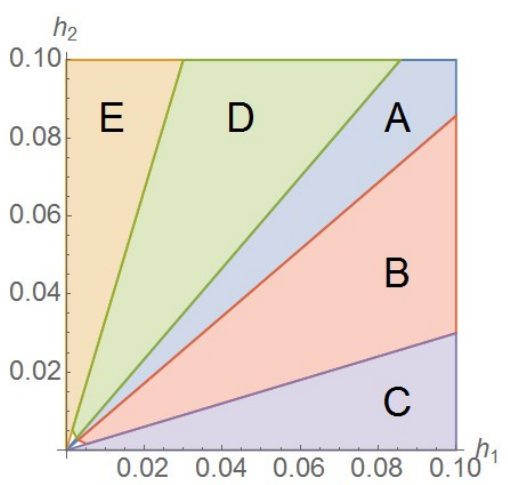

(b) $\mathrm{B}=100, \mathrm{C}=30, \mathrm{D}=30$

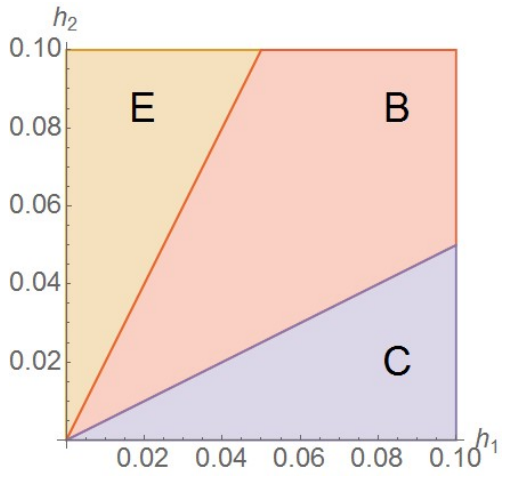

(d) $\mathrm{B}=100, \mathrm{C}=50, \mathrm{D}=50$

Figure 3 - Violent and non-violent equilibria for different parameter values

A new polarization indicator A new indicator of polarization can be derived from Condition (2), considering the simple case where $Q\left(h_{i}, h_{j}\right)$ takes the form of a Tullock contest success function $Q\left(h_{i}, h_{j}\right)=h_{i} /\left(h_{i}+h_{j}\right)=\pi_{i}=1-\pi_{j}$ where $\pi_{i}$ and $\pi_{j}$ are the share of violent supporters associated with parties $i$ and $j$ respectively. Inequality (2) is 
then equivalent to:

$$
\begin{aligned}
& \pi_{i}\left|\frac{0.5-\pi_{i}}{0.5}\right|+\left(1-\pi_{i}\right)\left|\frac{0.5-\pi_{i}}{0.5}\right|<1-2 \frac{C+D}{B+D} \\
& \Leftrightarrow P_{S} \equiv 1-\sum_{k=1}^{N} \pi_{k}\left|\frac{0.5-\pi_{k}}{0.5}\right|>2 \frac{C+D}{B+D}
\end{aligned}
$$

where $N=2$ is the number of parties. Interestingly, the left-hand side of inequality (3), denoted $P_{S}$, is very similar to the polarization index $R Q$ proposed by Garcia-Montalvo and Reynal-Querol (2005b):

$$
R Q=1-\sum_{k=1}^{N} \pi_{k}\left(\frac{0.5-\pi_{k}}{0.5}\right)^{2}
$$

The only difference between the indicators is that the square function in the $R Q$ index is replaced by the absolute value function in the new index. These two indicators are depicted on Figure 4 as a function of the number of parties $N$, assuming that parties have the same number of violent supporters. For the sake of comparison, the index of fractionalization is also depicted:

$$
F R A C=\sum_{k=1}^{N}\left(1-\pi_{k}\right) \pi_{k} .
$$

Figure 4 illustrates that the indexes $P_{S}$ and $R Q$ are close to 1 when $N=2$, and close to 0 when $N$ approaches 1 or when $N$ tends to infinity. Both indicators measure polarization between violent supporters, but the new index proposed in this paper is slightly more sensitive to departures from the maximum in $N=2$.

\subsection{Unilateral violence}

The resolution of the model for unilateral violence is similar to the bilateral case. Mathematical proofs are therefore relegated to the appendix for the sake of brevity. 


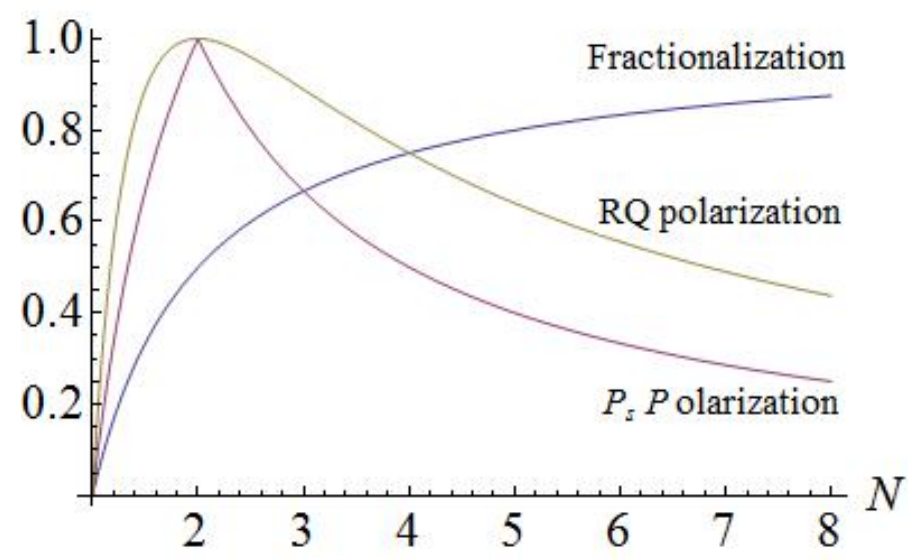

Figure 4 - Indexes of fractionalization $F R A C$, polarization $R Q$ from (3), and polarization $P_{S}$ from inequality (3).

Violent equilibria Without loss of generality, it is assumed that $v_{1}>v_{2}$. The following proposition characterizes the violent sub-game perfect Nash Equilibria of the game.

Proposition 2. Both parties engage in unilateral violence if:

$$
\left\{\begin{array}{l}
0.5<v_{1}<0.5+\delta\left(h_{1}+h_{2}\right) \\
q\left(h_{1}\right) q\left(h_{2}\right)>C / B \\
B-C-q\left(h_{2}\right) D>B\left(1-q\left(h_{1}\right)\right) q\left(h_{2}\right)>C+q\left(h_{1}\right) D
\end{array}\right.
$$

Only the electorally weakest party (party 2) engages in unilateral violence if:

$$
\left\{\begin{array}{l}
0.5<v_{1}<0.5+\delta\left(h_{1}+h_{2}\right) \\
B /(B+D)>q\left(h_{2}\right)>C / B \\
q\left(h_{1}\right) q\left(h_{2}\right)<C / B
\end{array}\right.
$$

Proof. The proof is presented in Appendix A.

Conditions (6) and (9) have a similar interpretation to condition (1). For violence to occur, the election should be sufficiently close such that the leading party (here party 1) can be defeated in case of electoral violence. As for bilateral violence, tight electoral competition and high numbers of violent supporters are complementary factors of violence. 
Conditions (7), (8), (10) and (11) are more complex to interpret because of nonlinearities. They are represented in Figures 5(a) to 5(c) for different parameter values.

Four types of equilibria are distinguished. Party 2 remains peaceful in the second stage if its number of violent supporters is low in absolute terms (white area labeled A), or low compared to the number of violent supporters of party 1 (white area labeled $\left.\mathrm{A}^{\prime}\right)$. In this case, party 1 is assured of winning the election without engaging in violence. Elsewhere, party 2 resorts to violence in stage 2 if party 1 chooses to actively participate in the election in stage 1 . In reaction, party 1 will either respond with violence, engage in political campaigning but not in violence, or refrain from political campaigning in the first stage.

The blue area labeled B characterizes the Nash Equilibrium in which both parties resort to violence. Intuitively, party 2 resorts to violence and party 1 responds to violence with violence if both parties have a reasonable chance of making a successful violent move (Condition (7)) and if violence is not too costly in terms of direct cost $C$ and expected damage cost $D$ (Condition (8)).

The hatched green area labeled C characterizes the Nash Equilibrium in which only the electorally weakest party (party 1 here) perpetrates unilateral violence (Conditions (10) and (11)). This equilibrium occurs if two conditions are jointly satisfied. First, the probability $q\left(h_{2}\right)$ that party 2 is successful in its violent move must be large, such that party 2 resorts to violence, but this probability cannot be too large otherwise party 1 withdraws from the election to avoid damages $D$ (Condition (10)). Second, the probability $q\left(h_{1}\right)$ that a violent move of party 1 is successful must be low, implying that it does not make sense for party 1 to engage in violence and bear the cost $C$ (Condition (11)).

Party 2 does not participate in the political campaign if party 2 is much stronger than party 1 in terms of violent supporters (yellow area labeled D). In doing so, party 1 avoid the harmful consequences of violence perpetrated by party 2 . 


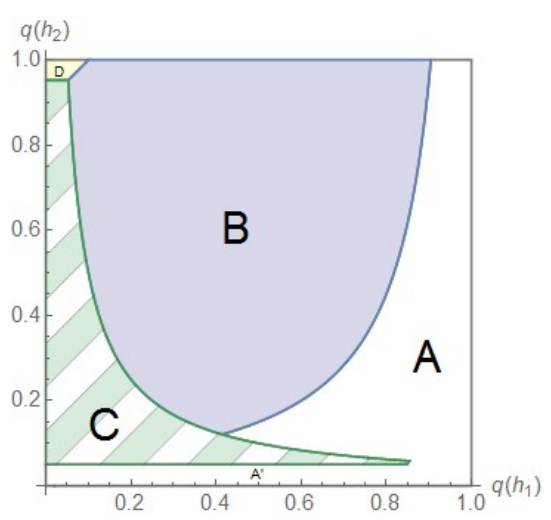

(a) $C$ and $D$ are low $(\mathrm{C}=5, \mathrm{D}=5)$

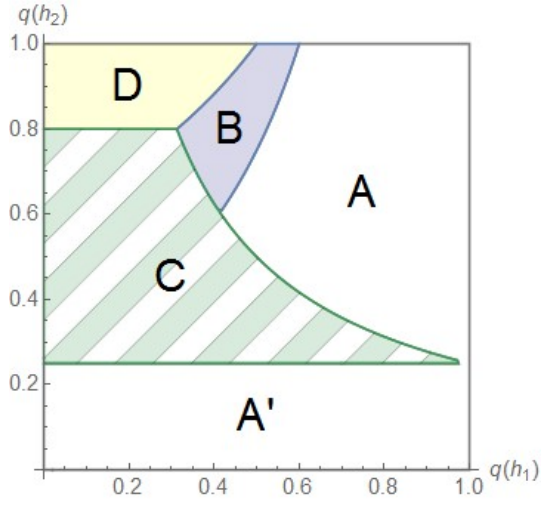

(b) $C$ and $D$ are intermediate $(\mathrm{C}=25, \mathrm{D}=25)$

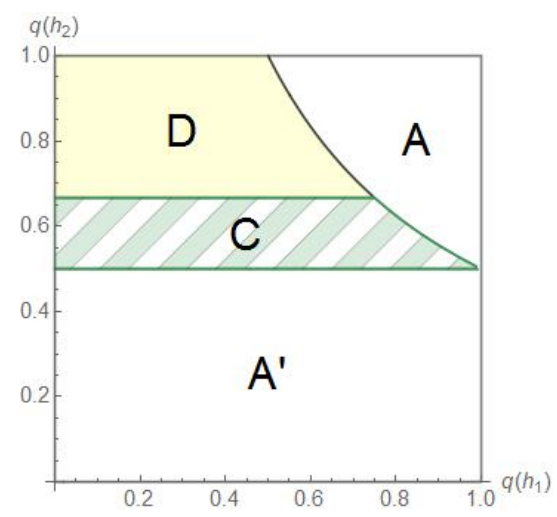

(c) $C$ and $D$ are high $(\mathrm{C}=50$, $\mathrm{D}=50)$

Figure 5 - Unilateral violence $(B=100)$. The blue plain area delimits the necessary conditions (7) and 8 under which both parties engage in unilateral violence. The green hatched area delimits the necessary condition (10) under which only the weakest party in terms of violent capacity engages in unilateral violence.

\subsection{Polarization between violent supporters and violence}

In Section 2.2, I concluded that bilateral violence only occurs if parties have similar numbers of violent supporters (Figure 2(b)). From Figures 5(a) to 5(c), we observe that the relationship between unilateral violence and the distribution of violent supporters is much less straightforward than for bilateral violence. In particular, the relationship seems to heavily depend on the cost of violence for the perpetrator $(C)$ and for the victim $(D)$.

I performed a Monte Carlo experiment to analyze the relationship between the distribution of violent supporters and violence. I randomly selected 10,000 observations in the $h_{1}, h_{2}$ space. Based on these observations, I calculated a polarization indicator following equation (3). I determined whether bilateral violence would occur using condition 
Table 1 - Correlation between bilateral violence and polarization $(\mathrm{B}=100, "=$ " $=$ no violence)

\begin{tabular}{l|cccccccccc}
\hline Cost of & \multicolumn{10}{c}{ Damages from violence (D) } \\
violence $(\mathrm{C})$ & 5 & 10 & 15 & 20 & 25 & 30 & 35 & 40 & 45 & 50 \\
\hline 5 & 0.63 & 0.73 & 0.79 & 0.83 & 0.86 & 0.86 & 0.86 & 0.85 & 0.83 & 0.8 \\
10 & 0.74 & 0.8 & 0.84 & 0.86 & 0.86 & 0.86 & 0.84 & 0.82 & 0.78 & 0.74 \\
15 & 0.81 & 0.85 & 0.86 & 0.86 & 0.85 & 0.83 & 0.8 & 0.76 & 0.7 & 0.64 \\
20 & 0.85 & 0.86 & 0.86 & 0.84 & 0.81 & 0.77 & 0.72 & 0.66 & 0.58 & 0.48 \\
25 & 0.86 & 0.85 & 0.83 & 0.79 & 0.74 & 0.68 & 0.6 & 0.49 & 0.35 & - \\
30 & 0.84 & 0.81 & 0.76 & 0.69 & 0.61 & 0.51 & 0.37 & - & - & - \\
35 & 0.78 & 0.72 & 0.63 & 0.53 & 0.38 & - & - & - & - & - \\
40 & 0.66 & 0.55 & 0.39 & - & - & - & - & - & - & - \\
45 & 0.41 & - & - & - & - & - & - & - & - & - \\
50 & - & - & - & - & - & - & - & - & - & - \\
\hline
\end{tabular}

Table 2 - Correlation between unilateral violence and polarization $(\mathrm{B}=100)$

\begin{tabular}{l|cccccccccc}
\hline Cost of & \multicolumn{10}{|c}{ Damages from violence (D) } \\
violence $(\mathrm{C})$ & 5 & 10 & 15 & 20 & 25 & 30 & 35 & 40 & 45 & 50 \\
\hline 5 & 0.41 & 0.35 & 0.3 & 0.25 & 0.21 & 0.17 & 0.14 & 0.11 & 0.08 & 0.05 \\
10 & 0.35 & 0.29 & 0.23 & 0.19 & 0.15 & 0.11 & 0.08 & 0.06 & 0.04 & 0.01 \\
15 & 0.25 & 0.19 & 0.15 & 0.11 & 0.08 & 0.06 & 0.04 & 0.03 & 0.01 & -0.01 \\
20 & 0.14 & 0.1 & 0.07 & 0.05 & 0.04 & 0.03 & 0.02 & 0.01 & -0.01 & -0.01 \\
25 & 0.05 & 0.03 & 0.02 & 0.02 & 0.02 & 0.01 & 0.01 & 0.01 & 0.02 & 0.03 \\
30 & -0.01 & -0.01 & 0 & 0 & 0.01 & 0.01 & 0.03 & 0.04 & 0.06 & 0.08 \\
35 & -0.04 & -0.02 & -0.01 & 0 & 0.02 & 0.04 & 0.06 & 0.08 & 0.09 & 0.1 \\
40 & -0.05 & -0.02 & 0 & 0.02 & 0.05 & 0.07 & 0.09 & 0.1 & 0.11 & 0.12 \\
45 & -0.04 & -0.01 & 0.02 & 0.05 & 0.07 & 0.09 & 0.11 & 0.12 & 0.12 & 0.13 \\
50 & -0.02 & 0.01 & 0.04 & 0.06 & 0.08 & 0.1 & 0.11 & 0.12 & 0.13 & 0.13 \\
\hline
\end{tabular}

(2), and whether unilateral violence would occur using equations (7), (8), (10), and (11). I then calculated the correlation between the polarization indicator and the number of parties engaging in violence. This process was repeated a hundred times for different parameter values. Averaged results are shown in Table 1 for bilateral violence, and Table 2 for unilateral violence.

The results show that the correlation between bilateral violence and polarization between violent supporters is high, ranging between 0.35 and 0.86 . No violence is perpetrated when the costs of perpetrating or facing violence are high, in line with Figures 3(c) and $3(\mathrm{~d})$.

The predictions are different for unilateral violence. The correlation between unilat- 
eral violence and polarization between violent supporters is moderate when the costs of perpetrating and facing violence are low. In line with Figure 5(a), violence does not emerge if one of the two parties is much stronger than the other in terms of violent supporters. The correlation vanishes, however, when these costs are intermediate or high, in line with Figure 5(b) and 5(c). In this latter case, only the electorally weakest party has the incentive to engage in violence. It does so only if it is sufficiently more powerful than its rival in terms of violent supporters, that is, when the polarization between violent supporters is low.

\subsection{Extensions to more than two parties}

The model is extended to $N \geq 2$ parties in Appendix B. This extension suggests that political competition is best captured by an index of fractionalization between political parties rather than an indicator of political polarization. Indeed, when fractionalization is high, the extended version of Condition (1) is satisfied for a large number of parties, thereby increasing the likelihood that at least two parties find it optimal to engage in violence. In contrast, electoral violence is triggered by polarization between violent supporters, and not by their fractionalization. The incentive for a party to engage in violence is indeed higher if it faces only one competitor with similar violent capacity, rather than many competitors that are equally strong.

However, as explained in Appendix B, whether it is polarization or fractionalization that matters rests on a series of assumptions, including the public or private nature of the payoff, the functional form of the success contest function, and the correlation between parties' expected score without violence $v_{i}$ and parties' number of violent supporters $h_{i}$. For example, Esteban and Ray (2011) and Esteban et al. (2012b) show that fractionalization is what matters when the payoff from violence is private (such as looted resources), mainly because group size dilutes individual benefits. By contrast, polarization is key when the payoff from violence is public (such as political power or prestige) and hence undiluted by one's own group size. In the present model, the net payoff $B-C$, is assumed to be a public good accessible to all members of the winning party, which leads to the 
prediction that polarization between violent supporters matters more than their fractionalization. Assuming a private payoff would lead to a different prediction. Whether the payoff from election violence is public or private is unclear and depends on the context. The reality is often not binary: payoffs are often partly public and partly private. Therefore, whether it is fractionalization or polarization that matters is mostly an empirical question.

\subsection{Closing the model}

So far, the models for bilateral and unilateral violence have been solved separately. In reality, parties can employ a variety of violent tactics simultaneously. The superimposition of Figures 2(b) and 5(a), for example, suggests that it might be optimal for parties to engage in both bilateral and unilateral violence under certain circumstances. Similarly, the superimposition of Figures 5(a) to 5(c) shows that parties may seek to engage in both "low-cost" unilateral violence (e.g. intimidation) and "high-cost" unilateral violence (e.g. murders).

When multiple violent tactics are simultaneously available, parties will simply weigh the expected costs and benefits of each strategy. These costs and benefits are expected to vary with the type of violence and the context. Killing an opponent is expected to be more costly than intimidating a victim, except if the judicial system is highly inefficient or skewed toward the perpetrator. The likelihood of success depends, for example, on the availability of weapons, on the presence of bodyguards, and on the skills and temper of the perpetrator. The benefit of killing an opponent depends on his or her popularity and on the reaction of voters. Similarly, the reaction of voters to intimidation or clashes between violent supporters will depend on their personal and political sensitivities.

These simplified examples illustrate that the parameters $C$ and $D$ and the functional forms $q()$ and $\delta()$ are highly contextual. In practice, propositions 1 and 2 should therefore be interpreted as necessary (but not sufficient) conditions for the occurrence of preelectoral violence. 


\subsection{Summary of predictions}

The predictions of the model are summarized in Table 3. The table distinguishes between three types of violence.

1. Clashes between parties fall into the bilateral violence category. For this type of violence, the transfer of votes from the loser to the winner of a violent contest is likely to be increasing with the total number of violent supporters. Clashes are therefore expected to take place in situations of close political competition with a high number of violent supporters whose distribution is polarized.

2. Acts of intimidation are unilateral acts of violence for which the expected cost of committing the act is relatively low. The transfer of votes to the winner is expected to be increasing in the number of violent supporters of the violent parties. The predictions of the model are similar to those for clashes, except that the relationship between violence and polarization between supporters is more tenuous. The incidence of this type of violence also increases with political competition and the number of violent supporters.

3. Assaults, murders and attempted murders are categorized as unilateral violence with high expected cost to the perpetrator and the victim. Assaults and murders are likely to occur when political competition is tight and when violent supporters are numerous. The correlation between violence and polarization between rival supporters is expected to be low for this category of violent acts.

\begin{tabular}{l|c|c} 
& \multicolumn{2}{|c}{ Correlation with: } \\
& $\begin{array}{c}\text { Pol. Comp } \times \\
\text { \# supporters }\end{array}$ & $\begin{array}{c}\text { Violent supporters } \\
\text { Polarization }\end{array}$ \\
\hline Clashes (bilateral violence) & + & ++ \\
Intimidation (low-cost unilateral violence) & + & + \\
Murder (high-cost unilateral violence) & + & 0 \\
\hline \hline All types & + & +
\end{tabular}

Table 3 - Main predictions of the model 


\subsection{What is new?}

The model incorporates six innovations that are essential to generate these original predictions. The two-stage structure of the game (innovation 1) and the assumption that violence is costly for the victim (innovation 2) imply that parties withdraw from the election if they expect to lose the election and to be harmed by electoral violence. This possibility of "escaping violence" explains why violence is unlikely to emerge in the presence of a party with a much stronger violent capacity. Violence is also costly for the perpetrator and its outcome is uncertain (innovation 3). ${ }^{13}$ This implies that parties refrain from violence if they have weak violent capacities, or if they are sure to win or lose the election. The first three innovations are key to reach the conclusion that polarization between violent supporters matters.

The new model assumes a discrete payoff $B$ for the party winning the election (innovation 4). This assumption leads to the prediction that political competition matters: parties only engage in violence if electoral competition is close enough, such that violence can affect the outcome of the election. The supplementary share of voters obtained through violence depends on the number of violent supporters of the parties involved (Innovation 5). ${ }^{14}$ This assumption implies that political competition and the number of violent supporters are complementary factors of violence.

The last innovation relates to the types of violent events analyzed. Because bilateral violence requires the involvement of both parties, these should be similar both in terms of initial support and violent capacity for bilateral violence to emerge. This requirement is weaker or absent for unilateral violence.

These innovations and associated assumptions are reasonable and very general. They are therefore expected to be valid in most contexts and, in particular, in the context of

\footnotetext{
${ }^{13}$ In contrast, Chaturvedi (2005) considers that the resources a party invests in violent campaigning automatically deter a share of its rival's voters from voting. Similarly, all soft-base voters abstain from voting in Collier and Vicente (2012) as long as one party engages in intimidation, and the cost of intimidation is "set at an arbitrarily low level".

${ }^{14}$ In contrast, Skaperdas and Grofman (1995), Chaturvedi (2005) and Collier and Vicente (2012) assume that the voting gain from violence is proportional to the initial support of the rival party. This latter assumption implies that electoral violence is more rewarding for parties that are electorally weak, against those that are electorally strong.
} 
Burundi. Parties are indeed allowed to withdraw from the elections in most contexts (Innovation 1). In Burundi, for example, many parties withdrew from the presidential and parliamentary elections after the municipal elections. It is obvious that electoral violence is costly for the victim and for the perpetrator (Innovations 2 and 3). The new model does not impose constraints on these costs, which can be large or low. The fact that not all violent moves are successful in the new model is realistic (Innovation 3). For example, assassination attempts often fail and clashes between different parties generally result in a winner and a loser. In most contexts (even in proportional systems), parties obtaining a majority of votes are in charge of executive mandates, which brings monetary and non-monetary gains. This justifies the payoff $B$ allocated to the party winning the election (Innovation 4). The assumption that the supplementary share of votes obtained through violence depends on the number of violent supporters involved seems reasonable (Innovation 5): clashes between large groups are expected to have a more important impact on voters than minor fights between few supporters. Finally, clashes, intimidation, and murders of course have different success contest functions and different cost functions (Innovation 6).

\section{Historical background: the 2010 elections in $\mathrm{Bu}-$ rundi}

Burundi is a small landlocked country situated in the Great Lakes region of sub-Saharan Africa. This densely populated country has about 10 million inhabitants, among whom 90\% live in rural areas. The Hutu and the Tutsi ethnic groups represent $82 \%$ and $17 \%$ of the population respectively. ${ }^{15}$ According to the World Bank Indicators, the country's GDP per capita was USD 251 in 2012. Burundi is ranked 178 out of 187 countries according to the Human Development Index.

Since its independence from Belgium in 1961, Burundi has been shattered by ethnicbased violence between the Hutu majority and the Tutsi minority. Between 1966 and

\footnotetext{
${ }^{15}$ Afrobarometer data (2012).
} 
1993, a group of Tutsi officers ruled the country and fiercely repressed any Hutu opposition. In 1993, following mounting international pressure, presidential elections were organized and won by the Hutu candidate, Melchior Ndadaye. His efforts to reform the Tutsi-controlled army led to his assassination amidst a failed military coup, after only three months in office. His assassination triggered a series of tit-for-tat massacres between Hutu and Tutsi and ultimately sparked a 16 year-long civil war.

Despite a promising Peace and Reconciliation Agreement signed in Arusha in August 2000, the civil war dragged on because the two largest Hutu rebel groups, the CNDDFDD and the FNL-Palipehutu, rejected the peace agreement. They continued to fight against the government of transition. In 2003, the CNDD-FDD rebel group signed a peace agreement and turned into a political party. Its combatants were either integrated into the national army, or benefited from a generous demobilization program. Their leader Pierre Nkurunziza emerged victorious from the 2005 electoral process. It took until December 2008 to sign a final agreement between the government and the last Hutu rebel group, the FNL-Palipehutu. In turn, the FNL-Palipehutu transformed into a political party and its combatants benefited from the demobilization program (D'Aoust et al. 2016).

Elections were conducted in 2010 in a climate of uncertainty and violence. Five consecutive polls were organized to select municipal, presidential, parliamentary, senatorial and local representatives. Despite its local dimension, the first ballot assumed a strategic role (ICG 2011). In the absence of electoral survey, nobody knew who would would win. Parties thought that the winner of the first election would gain a decisive advantage for the next ballots (ICG 2011; Palmans 2012). Therefore, "even the first communal elections were very national: people voted for parties, not for individual candidates, after a campaign that was run by national political leaders, not on the basis of communal development programmes" (Vandeginste 2011). Municipal elections were seen, "in the mind-set of the people, as being the first round of the presidential election" (Palmans 2012). At least five parties were thought to have a decent chance of winning, among which were the parties stemming from the former Hutu rebel groups CNDD-FDD and FNL. The main parties in Burundi in 2010 are listed in Table 4, together with their ethnic orientation, their elec- 
Table 4 - Main parties and former rebel groups in 2010

\begin{tabular}{lcccccc}
\hline \hline Party & $\begin{array}{c}\text { Year of } \\
\text { creation }\end{array}$ & $\begin{array}{c}\text { Ethnicity } \\
\text { of leader }\end{array}$ & $\begin{array}{c}\text { \% of votes } \\
\text { in } 2010\end{array}$ & $\begin{array}{c}\text { Ex-rebel } \\
\text { group }\end{array}$ & $\begin{array}{c}\text { No. of demob. } \\
\text { (share) }\end{array}$ & $\begin{array}{c}\text { Correlation votes } \\
\text { \& share demob. }\end{array}$ \\
\hline CNDD-FDD & 1998 & Hutu & 64.03 & Yes & $6874(39 \%)$ & 0.59 \\
FNL & 1999 & Hutu & 14.15 & Yes & $6029(34.2 \%)$ & 0.57 \\
UPRONA & 1957 & Tutsi & 6.25 & No & & \\
FRODEBU & 1986 & Hutu & 5.43 & No & & \\
MSD & 2009 & Tutsi & 3.75 & No & & \\
UPD & 2003 & Hutu & 2.21 & No & & \\
FRODEBU-Nyakuri & 2008 & Hutu & 1.36 & No & \\
CNDD & 1994 & Hutu & 1.26 & Yes & $1372(7.8 \%)$ & 0.76 \\
MRC & 2001 & Tutsi & 0.62 & No & & \\
PALIPE-Agakiza & 1980 & Hutu & 0.24 & Yes & $578(3.3 \%)$ & 0.02 \\
FROLINA & 1990 & Hutu & 0.20 & Yes & $540(3.1 \%)$ & -0.04 \\
KAZE-FDD & 2005 & Hutu & 0.00 & Yes & $361(2 \%)$ & - \\
FNL dissidents & & Hutu & - & Yes & $1594(9 \%)$ & - \\
FNL Icanzo & 2001 & Hutu & - & Yes & $278(1.6 \%)$ & \\
\hline \hline
\end{tabular}

toral results at the municipal election, and their number of demobilized combatants. As reported by Vandeginste (2011), elections were "perceived by Burundi's elite as rewarding (and therefore encouraging) a governance system based on strong presidentialism and big man clientelism. Programmatic and ideological differences or debates about specific policy issues hardly played any role". Violence has been pervasive throughout the electoral process. In such a context, the CNDD-FDD party of the president Pierre Nkurunzia won the municipal ballot swiftly with $64 \%$ of the votes. The FNL party of Agathon Rwasa received only $14 \%$ of the vote. Following their crushing defeat, opposition parties accused the CNDD-FDD of massive fraud and jointly decided to boycott the four following ballots. The municipal election was indeed a turning point. Left without credible opposition, the incumbent president was re-elected with $95 \%$ of the vote.

\section{Identification Strategy}

The empirical analysis aims to assess how political competition and the distribution of violent supporters affected the incidence of pre-electoral violence at the municipal level during the 2010 elections in Burundi (there are 129 municipalities in Burundi). 


\subsection{Data}

I combine data on election and violence from Colombo et al. (2019) with data on night light intensity and geography attributes from Henderson et al. (2018).

Electoral violence. Data on electoral violence was collected by the International Foundation for Election Systems (IFES) as part of the Amatora mu Mahoro - Elections in Peace - project (IFES 2010). IFES used the EVER methodology (Elections Violence Education and Resolution), which has been successful in monitoring and preventing electoral violence in over a dozen countries since 2003. About 450 field reporters were extensively trained in election monitoring. ${ }^{16}$ From the 26th of April to the 12th of September 2010, they verified and recorded 519 violent incidents. ${ }^{17}$ Given the strategic character of the first round of election (ICG 2011; Palmans 2012; Vandeginste 2011) and because a boycott affected other polls, this paper focuses on the 158 violent events that took place before the first round of the electoral cycle. ${ }^{18}$ As shown in Section 6, similar results are obtained when focusing on the 374 events that took place before the last round of election. ${ }^{19}$ In section 6.5, I also study the determinants of post-electoral violence, focusing on the 221 violent events that took place after the municipal elections.

The incidents are classified into three groups: (1) clashes between groups, (2) acts of intimidation, and (3) cases of assaults and murders. ${ }^{20}$ An example of a clash between

\footnotetext{
${ }^{16}$ IFES has endorsed the "Declaration of Global Principles for Non-Partisan Election Observation and Monitoring By Citizen Organizations" and the "Code of Conduct for Non-Partisan Citizen Election Observers and Monitors". These documents, which are endorsed by over 160 nonpartisan election monitoring organizations in more than 75 countries, provide a series of principles and pledges to promote the "highest ethical standards for impartiality and accuracy" in election observation and monitoring.

${ }^{17}$ Incidents were reported in three steps. First, field reporters had to send text messages when they witnessed or heard about an incident. The Ushahidi web platform - which was developed by Kenyans in response to the electoral violence that shook the country in $2007 / 2008$ - was used for rapid sharing of information about incidents via SMS. Second, the data collecting agents who received the text messages had to call back the field reporters to gather more information about the incident. A full report was written for the Ushaidi website. Finally, the field reporter who signaled the incident was requested to submit a detailed report of the incident after a week by filling out a form with specific information regarding to time, location and type of incident. Incidents had to be reported by at least two different sources to be recorded in the database. The report Amatora Mu Mahoro (2010) provides more detail on data collection as well as a description of the violent events recorded.

${ }^{18}$ The electoral cycle started on the 24th of May 2010, with the municipal elections (commune level).

${ }^{19}$ The electoral cycle ended on the 7th of September 2010 with the local election (hill level).

${ }^{20}$ The analysis relies on the classification made by IFES. Some of the original categories are however regrouped because they are not containing enough observations. In the present analysis, the "Intimida-
} 
groups occurred on the 16th of May 2010 in Kayanza and was reported as follows by a field reporter: "In Kivuzo, FNL and CNDD-FDD supporters fought each other. Six FNL members were imprisoned and 3 phones were lost." Most events involving intimidation relate to demobilized combatants threatening the civilian population if they do not vote for their party. For example, on the 20th of May 2010 in Mutaho, "CNDD-FDD militants armed with spears, machetes, and batons walked in front of houses of FNL militants to terrorize them." This category also includes acts of destruction, as illustrated by the two following examples: "In Bugorora, a supporter of the CNDD-FDD party burned an emblem of the FNL party" (6th of May 2010) and "During the night, local offices of CNDD-FDD have been damaged in the municipality of Gishubi, Murangara, Munyinya and Bukwavu. Perpetrators are not yet identified"(29th of April 2010). An example of an event classified as murder occurred on the 16th of May in Burenza: "A man was stabbed by unidentified people. In the past, he has been a member of the CNDD-FDD, but he left this party on the 9th of May to become a FNL militant." In line with the theoretical model, clashes are categorized as bilateral violence, while acts of intimidation, assaults and murders are categorized as unilateral violence. ${ }^{21}$

Descriptive statistics are presented in Table 5. A correlation table is shown in Appendix C.

Political competition. In the context of U.S. States, Besley et al. (2010) define "lack of political competition" as "an electoral advantage of one of two political parties". An indicator of political competition should capture whether elections are contested. With more than two parties, political competition is best measured by an index of fractional-

tion" category regroup cases of verbal harassment (26 events), destruction (19 events) and intimidation (29 events). The category "Assaults and Murders" include harms to physical integrity (6 events), murders (5 events), attempt murders (3 events), and physical harm or torture (14 events). The misclassification of a few events can of course not be ruled out, but this risk is marginal and probably not systematic.

${ }^{21}$ Given the nature of the phenomenon under scrutiny, information on the perpetrator(s) of violence is unavailable for the majority of violent acts (perpetrators avoid being identified), implying that this information cannot be used in the empirical analysis. Percentages of missing data are: $68.4 \%$ for destruction, $62.5 \%$ for murders, $20 \%$ for intimidation, $10.7 \%$ for clashes and $5 \%$ for assaults. Importantly, this absence of data on who is responsible for the violence is not generating any omitted variable bias, mismeasurement bias, or selection bias (all incidents will considered in the regressions). The only implication is that I am not able to consider dependent variables like "violence committed by the incumbent", or "violence committed by an opposition party". 
ization between political parties (Appendix B):

$$
\text { Political competition }_{m}=\sum_{i=1}^{N}\left(1-\pi_{i}\right) \pi_{i}
$$

where $\pi_{i}$ is the proportion of people who voted for party $i$. Political fractionalization can be interpreted as the probability that two randomly selected individuals from a given municipality voted for different parties in the municipal elections. ${ }^{22}$ The main indicator of political competition is constructed using the results of the 2005 municipal election. Similar results are obtained if political competition is based on the results of the 2010 municipal election, or if political competition in 2010 is instrumented for by political competition in 2005 (Reed 2015). Similar results are also obtained with an indicator measuring the difference in electoral results between the two most important parties in each municipality, in line with equation (1).

Polarization between violent supporters. In the context of Burundi, the role of violent supporters is likely to be played by ex-rebels who were demobilized at the end of the 1993-2009 civil war. Demobilized combatants have been reported to play an active role in electoral violence: "Since September 2009, Human Rights Watch has identified acts of violence initiated by supporters of several political parties, most often by members of their youth wings, which include large numbers of ex-combatants from the country's civil war. They are often persuaded - sometimes with party money - to intimidate political rivals with verbal threats, vandalism, and physical assaults." (Human Rights Watch 2010) The polarization index $P_{s}$ derived in inequality (3) is built using information on the affiliation of demobilized combatants and the location to which they returned. This information was gathered by the National Commission for Demobilization, Reinsertion and Reintegration. ${ }^{23}$

\footnotetext{
${ }^{22}$ Political polarization is not included in the regressions because this index is highly multicollinear with political fractionalization. The correlation between these two indicators is 0.79 , showing that they capture the same dynamics.

${ }^{23}$ The National Commission for Demobilization, Reinsertion and Reintegration kindly shared data on the affiliation, grade, location of return, location of origin and date of demobilization of 33,545 demobilized combatants.
} 


$$
\text { Violent supporters polarization }{ }_{m}=P_{s}=1-\sum_{i=1}^{N}\left|\frac{0.5-\pi_{i}}{0.5}\right| \pi_{i}
$$

where $\pi_{i}$ is the proportion of ex-combatants from each demobilized group. Regressions also include a measure of the density of demobilized combatants who returned to the municipalities (demobilized combatants per 1000 inhabitants).

Control variables. 15 control variables are included in the regressions to minimize the risk of omitted variable bias.

- Ethnic grievances: I control for the distribution of Hutu and Tutsi in the population, in line with the literature on ethnic grievances (Esteban et al. 2012a; GarciaMontalvo and Reynal-Querol 2005b). I consider an indicator of ethnic fractionalization $^{24}$ as well as a measure of the share of Hutu in the population. These variables are built using Afrobarometer data. ${ }^{25}$

- Past violence: I also control for past violence during the Burundian civil war using ACLED data. Omitting past violence could result in omitted-variable bias because violence can affect electoral outcomes (Bateson 2012; Blattman 2009; Bellows and Miguel 2009) and violence tends to be endemic and persistent (Collier 2008).

- Demographics: Because the benefits and costs of violence and politics can be very different in cities compared to rural areas, I control for population size and population density. These indicators are constructed using data from the 2008 Burundian census.

- Election results in 2005: I control for the share of votes obtained by each party during the 2005 elections, to prevent bias from unobserved variables affecting voters' choices.

\footnotetext{
${ }^{24}$ With two ethnic groups, fractionalization and polarization indicators are perfectly multicollinear.

${ }^{25}$ The 2012 Burundian Afrobarometer survey is representative at the provincial level. In order to avoid attenuation bias, variables related to ethnicity are therefore measured at the provincial level in regression with no fixed effect and regression with pair fixed effects. In regression with province fixed effects, I consider the average value in the municipality and in its neighbors, in order to avoid perfect multicollinearity.
} 
- Economic activity: In line with the greed versus grievances literature (Collier and Hoeffler 2004), I control for the level of economic activity using night light data from Henderson et al. (2018). ${ }^{18}$

- Geography attributes: Because previous research has shown that violence is correlated with geography and weather (Spolaore and Wacziarg 2016; Hsiang et al. 2013; Gleditsch et al. 2012; Buhaug et al. 2009), I control for terrain ruggedness, temperature (in Celsius), precipitation (mm/month), growing days, and for a dummy variable distinguishing the main biome (tropical moist forest vs. savanna.) using data from Henderson et al. (2018). ${ }^{26}$

As shown in Section 6, results do not significantly change if these control variables are removed from the regressions, or if other controls are added.

\subsection{Estimation method}

The count nature of electoral violence data motivates the application of a count response model. A chi-square goodness-of-fit test strongly rejects the null hypothesis that electoral violence data follow a Poisson distribution $(\mathrm{p}$-value $=0.00)$, indicating the presence of overdispersion in the dependent variable. Consequently, the identification strategy relies on the negative binomial regression model, which is more appropriate in the case of overdispersion (Hilbe 2011). The following equation is estimated:

$E\left(\right.$ Electoral Violence $\left.{ }_{m} \mid X_{m}\right)=\exp \left(\beta_{0}+\beta_{1}{\text { Political Comp }{ }_{m}}+\beta_{2}\right.$ Demob. Polarization $\left._{m}+C_{m}^{\prime} \delta\right)$

The matrix of control variables $C_{m}$ includes indicators of demobilized combatants density, Hutu share, ethnic fractionalization, past violence, population size, population density,

\footnotetext{
${ }^{26}$ The grid data of Henderson et al. (2018) considers 1/4 degree cells that do not perfectly match with the borders of municipalities in Burundi. For each municipality and each variable, I therefore calculated a weighted average over the relevant cells, with weights proportional to share of the municipality covered by each cell.
} 
Table 5 - Summary Statistics for the 129 Municipalities ("Communes") in Burundi

\begin{tabular}{|c|c|c|c|c|c|c|c|c|c|}
\hline & Mean & St. Dev. & Obs. & Min. & Max. & Total & $\begin{array}{c}\text { Moran's Stat. } \\
\text { (p-value) }\end{array}$ & \multicolumn{2}{|c|}{ R-squared } \\
\hline $\begin{array}{l}\text { Total } \\
\text { Tothe }\end{array}$ & 1.22 & 1.54 & 129 & 0 & 6 & 158 & $-0.06(0.26)$ & 0.12 & 0.47 \\
\hline Bilateral violence (clashes) & 0.43 & 0.92 & 129 & 0 & 5 & 56 & $-0.05(0.24)$ & 0.16 & 0.48 \\
\hline Unilateral violence (intimidation, assaults, murders) & 0.79 & 1.03 & 129 & 0 & 4 & 102 & $-0.07(0.13)$ & 0.12 & 0.46 \\
\hline Intimidation & 0.57 & 0.86 & 129 & 0 & 3 & 74 & $-0.05(0.21)$ & 0.12 & 0.48 \\
\hline \multicolumn{10}{|l|}{ Political competition } \\
\hline Political competition 2010 & 0.50 & 0.18 & 129 & 0.15 & 0.81 & & $0.67(0.00)$ & 0.72 & 0.83 \\
\hline Political competition 2005 & 0.48 & 0.18 & 129 & 0.08 & 0.83 & & $0.51(0.00)$ & 0.51 & 0.74 \\
\hline CNDD-FDD votes 2005 & 0.56 & 0.28 & 129 & 0.04 & 0.92 & & $0.79(0.00)$ & 0.79 & 0.89 \\
\hline UPRONA votes 2005 & 0.08 & 0.08 & 129 & 0.00 & 0.52 & & $0.29(0.00)$ & 0.22 & 0.65 \\
\hline FRODEBU votes 2005 & 0.26 & 0.21 & 129 & 0.04 & 0.96 & & $0.56(0.00)$ & 0.58 & 0.78 \\
\hline \multicolumn{10}{|l|}{ Demobilized combatants } \\
\hline Demobilized polarization & 0.58 & 0.18 & 129 & 0.00 & 1.00 & & $0.32(0.00)$ & 0.38 & 0.64 \\
\hline Demobilized fractionalization & 0.54 & 0.16 & 129 & 0.00 & 0.78 & & $0.43(0.00)$ & 0.44 & 0.7 \\
\hline Demobilized per 1000 inhab. & 2.13 & 2.13 & 129 & 0.14 & 12.72 & & $0.51(0.00)$ & 0.61 & 0.75 \\
\hline \multicolumn{10}{|l|}{ Ethnic distribution (prov. level) } \\
\hline Proportion of Hutu & 0.81 & 0.14 & 129 & 0.47 & 0.98 & & $0.68(0.00)$ & & 0.82 \\
\hline Ethnic Fractionalization & 0.27 & 0.14 & 129 & 0.03 & 0.50 & & $0.65(0.00)$ & & 0.8 \\
\hline \multicolumn{10}{|l|}{ Other controls } \\
\hline Past violence (ACLED data) & 17.64 & 23.01 & 129 & 0 & 106 & 2,276 & $0.32(0.00)$ & 0.38 & 0.65 \\
\hline Population size & 62,431 & 26,454 & 129 & 17,481 & 155,005 & $8,053,574$ & $0.24(0.00)$ & 0.3 & 0.6 \\
\hline Population density & 1,235 & 4,174 & 129 & 72 & 33,831 & & $0.44(0.00)$ & 0.42 & 0.73 \\
\hline
\end{tabular}

night light intensity, and geography attributes. The model specification is validated by Pearson's dispersion tests and link tests. In line with the predictions of the theoretical model, the empirical analysis tests if $\beta_{1}>0, \beta_{2}>0$.

In a second step, equation (14) is complemented with an interaction variable between the number of demobilized combatants and political competition:

$$
\begin{aligned}
E\left(\text { Electoral Violence }_{m} \mid X_{m}\right)= & \exp \left(\beta_{0}+\beta_{1} \text { Political Comp } \cdot m_{m}+\beta_{2}{\text { Demob. } \text { Polarization }_{m}}(15)\right. \\
& \left.+\beta_{3} \# \text { Demob } \cdot m+\beta_{4} \text { Political Comp }_{m} \times \# \text { Demob } \cdot m_{m}+C_{m}^{\prime} \delta\right)
\end{aligned}
$$

The objective is to assess whether the impact of political competition and the impact of ex-combatants' presence are reinforcing each other $\left(\beta_{4}>0\right)$. 
The risk of omitted variables is minimized by including control variables and geographic fixed effects. I will consider four sets of regressions. In the first set, I consider only variables of interest. In the second set, I include the control variables described in the previous section. In the third set, I further include province fixed effects, assuming that municipalities located in the same province are more likely to have similar unobserved characteristics.

In the last set of regressions, I use fixed effects to compare pairs of neighboring municipalities, assuming that the unobserved characteristics of municipalities with a common border are more likely to be similar (Goldstein and Udry 2008; Huillery 2009). I constructed a database that identifies each pair of neighboring municipalities with a dummy variable. These "pair" fixed effects are then included in the regressions to control for unobserved characteristics that are common among neighboring municipalities. ${ }^{27}$ Standard errors are clustered at three levels in order to account for the fact that each municipality may have several neighbors and be the neighbor of several other municipalities, implying that observations are duplicated in the dataset. ${ }^{28}$

In Table 5, I report the $R^{2}$ of regressions of each variable on province of pair fixed effects. Perhaps unsurprisingly, the $R^{2}$ with pair fixed effects are systematically larger than the $R^{2}$ with province fixed effects. This suggests that pair fixed effects are more likely to capture unobserved characteristics that are geographically correlated. For this reason, the pair fixed effects specification is the preferred one, although province and pair fixed effects lead to similar results. As discussed in Section 6, results are robust across a variety of specifications and tests, showing that omitted variables, reverse causality, the choice of functional forms, and spatial dependence are unlikely to significantly bias the results.

\footnotetext{
${ }^{27}$ There are 702 pairs of neighbors $(129 \times 5.44)$. Pairs of observations in 150 of 702 clusters $(21.4 \%)$ are characterized the same number of violent episodes. For these observations, electoral violence is fully explained by the fixed effects. The intra-class, or intra-pair, correlation is not statistically different from 0 , showing that a large share of the variation in electoral violence is left unexplained by fixed effects.

${ }^{28}$ The first level is the neighborhood. The second level accounts for the fact that each municipality may be the neighbor of several other municipalities. The third level captures the fact that municipalities have duplicates in the sample.
} 


\section{Empirical results}

The results with the aggregate measure of electoral violence are presented in Table 6 . Results without control variables and fixed effects are shown in columns (1) and (2). Control variables are added in columns (3) and (4). Province fixed effects are further included in columns (5) and (6). The matching procedure comparing pairs of neighboring municipalities is implemented in columns (7) and (8). Equation (14) is estimated in odd columns. Following equation (15), an interaction term between political competition and the density of demobilized combatants is included in even columns in order to test whether the impact of political competition and the impact of ex-combatants' presence are reinforcing each other.

The coefficients associated with political competition are positive but not statistically significant. As predicted by the theory, however, the coefficient associated with the interaction term between political competition and the density of demobilized combatants is positive and significant in all regressions. Figures 6(a) and 6(b) show the marginal effect of the number of demobilized combatants per 1,000 inhabitants and of political competition, based on column (6). When political competition is low, an increase in the density of demobilized combatants reduces the likelihood of violence, and when the density of demobilized combatants is low, an increase in political competition does not significantly increase the likelihood of electoral violence. By contrast, when political competition or the number of demobilized rebels is high, an increase in the other variable significantly increases the likelihood of electoral violence, indicating that these two variables are complementary factors of electoral violence. The overall relationship is represented on Figure 6(c). The predicted number of violent events (in log) is the highest when both political competition and the number of demobilized rebels are high.

The coefficient associated with the index of polarization between demobilized rebels is positive and statistically significant when control variables are included. The effect is larger when fixed effects are further included in the regressions. Based on column (6), a one standard-deviation increase in ex-rebels' polarization induces a $85 \%$ increase in the 


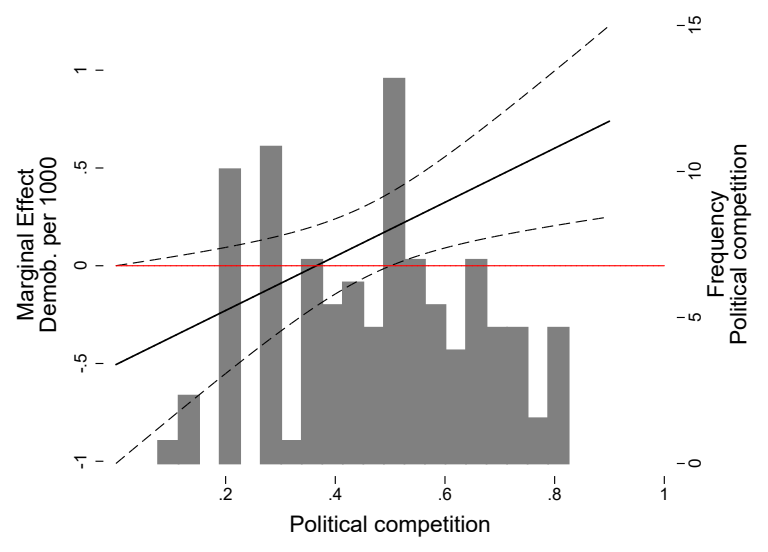

(a) Marginal effect of the number of demobilized as a function of political competition (95\% CI)

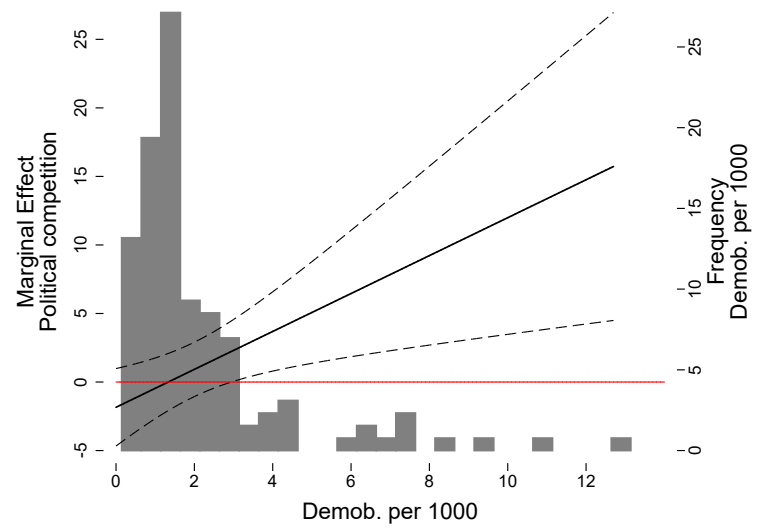

(b) Marginal effect of political competition as a function the number of demobilized $(95 \% \mathrm{CI})$

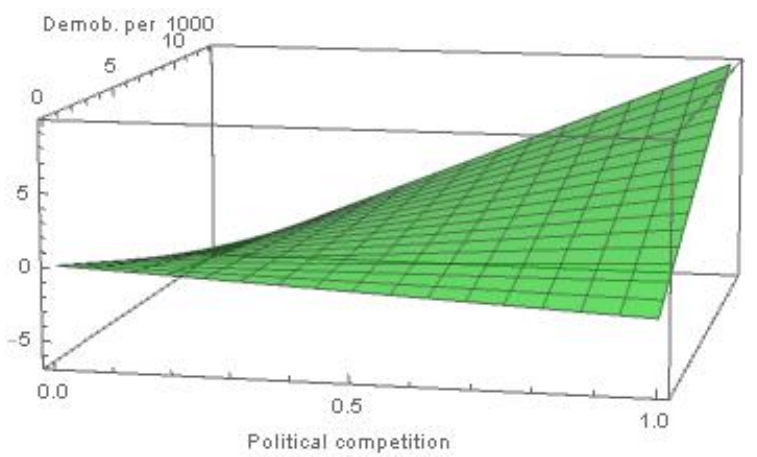

(c) Joint predicted effect of political competition and number of demobilized rebels

Figure 6 - Interpretation of interaction term between political competition and the number of demobilized combatants per 1,000 inhabitants (based on Table 6 column (8)) 
Table 6 - Impact of political competition and ex-rebels' polarization on the aggregate indicator of violence

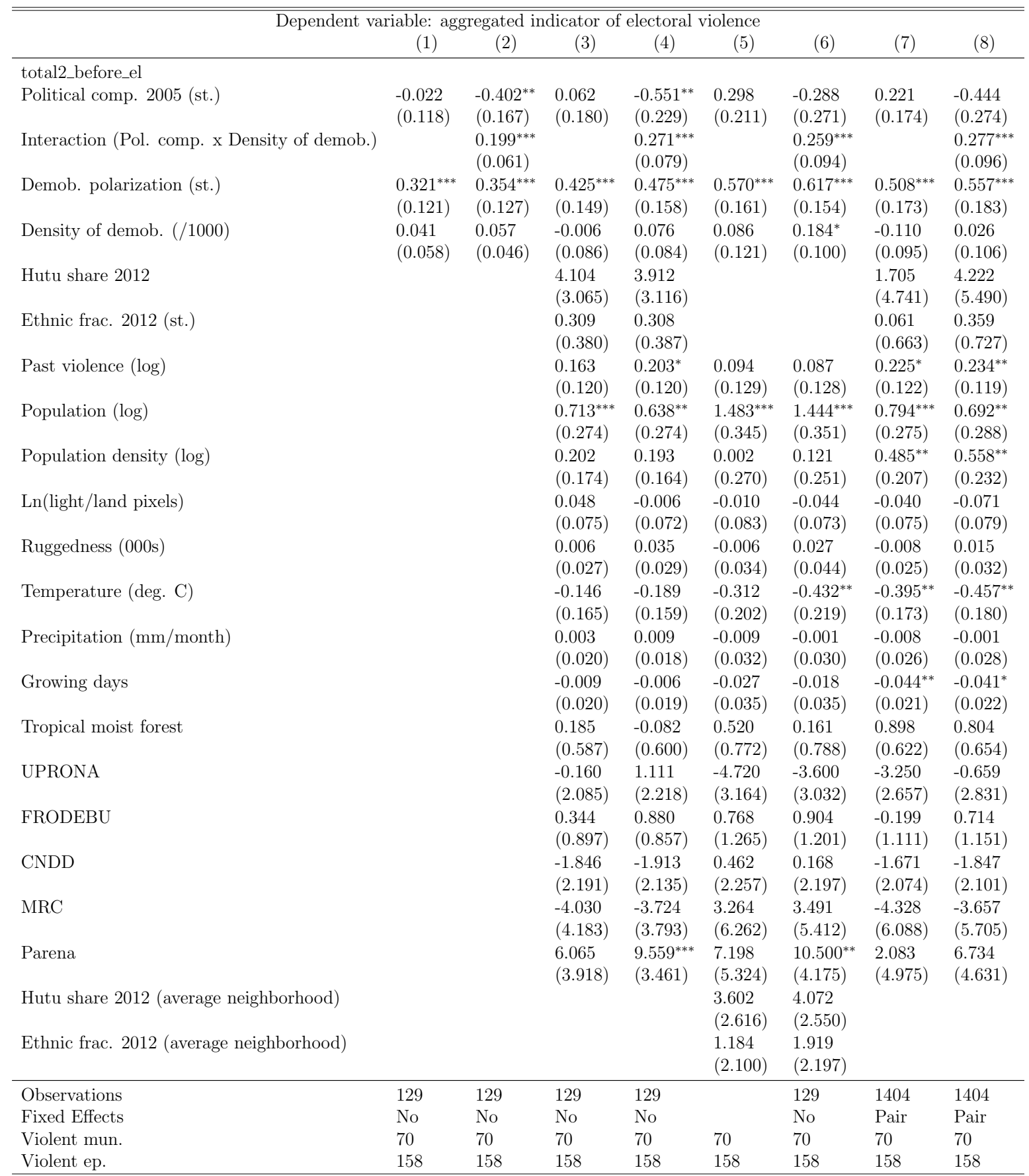

${ }^{*} p<0.10, * * p<0.05, * * * p<0.01$. The table reports negative binomial estimates. The unit of observation is the municipality. The indicator of political competition is a fractionalization index constructed using the results of the 2005 municipal elections. Pair columns include an interaction term between political competition and the density of demobilized rebels who returned in the municipality. Province fixed effects are included in columns (5) and (6). In columns (7) and (8), the data used identifies each pair of neighboring municipalities by a dummy variable (702 pairs and 1404 lines). These dummies are included in the regression as fixed effects. In columns (1) to (6), robust standard errors are reported in parentheses. In columns (7) and (8), multiway clustered-robust standard errors are reported in parentheses. 
predicted number of episodes of electoral violence. ${ }^{29}$ In accordance with the model, electoral violence is more likely to emerge in the presence of two groups of violent supporters of similar size.

Regarding control variables, results suggest that electoral violence was more likely to emerge in areas most affected by the civil war. There is also strong evidence that electoral violence incidence increases with population size. The coefficient associated with ethnic fractionalization is not significantly different from zero. Unlike the 1993 civil conflict, violence that disrupted the 2010 electoral process was not driven by ethnic grievances between Hutu and Tutsi. In accordance with this finding, Vandeginste (2011) explains that "this deethnicisation of electoral competition is largely due to the consociational powersharing arrangement laid down in the Arusha Agreement of 2000 and in the constitution of 18 March 2005. [...] Sharply contrasting with the 1993 general elections, the 2010 elections have only very minimally been affected by ethnic discourse. Electoral competition is no longer primarily a matter of ethnic competition".

Table 7 distinguishes the different types of violent event. To facilitate comparison, results with the aggregate indicator of electoral violence are reproduced in columns (1) and (2). Columns (3) to (6) distinguish between bilateral and unilateral violence. Columns (7) to (10) compare "low-cost" unilateral violence (intimidation) from "high-cost" unilateral violence (assaults and murders). For each category of events, I report the results of regressions with and without the interaction term between political competition and the density of demobilized combatants. The Panel A shows results without control variable and without fixed effect. In Panel B, control variables are included in the regressions. In order to minimize the risk of omitted variable bias, province fixed effects are further included in Panel C, while pair fixed effects are considered in Panel D.

Results in columns (3) and (4) confirm that polarization between demobilized combatants is critical for triggering bilateral violence, i.e. clashes between violent supporters. The coefficient associated with ex-rebels' polarization is positive and significantly differ-

\footnotetext{
${ }^{29}$ The interpretation in percentage term is derived from the formula $100 \times\left(e^{\beta}-1\right)$.
} 


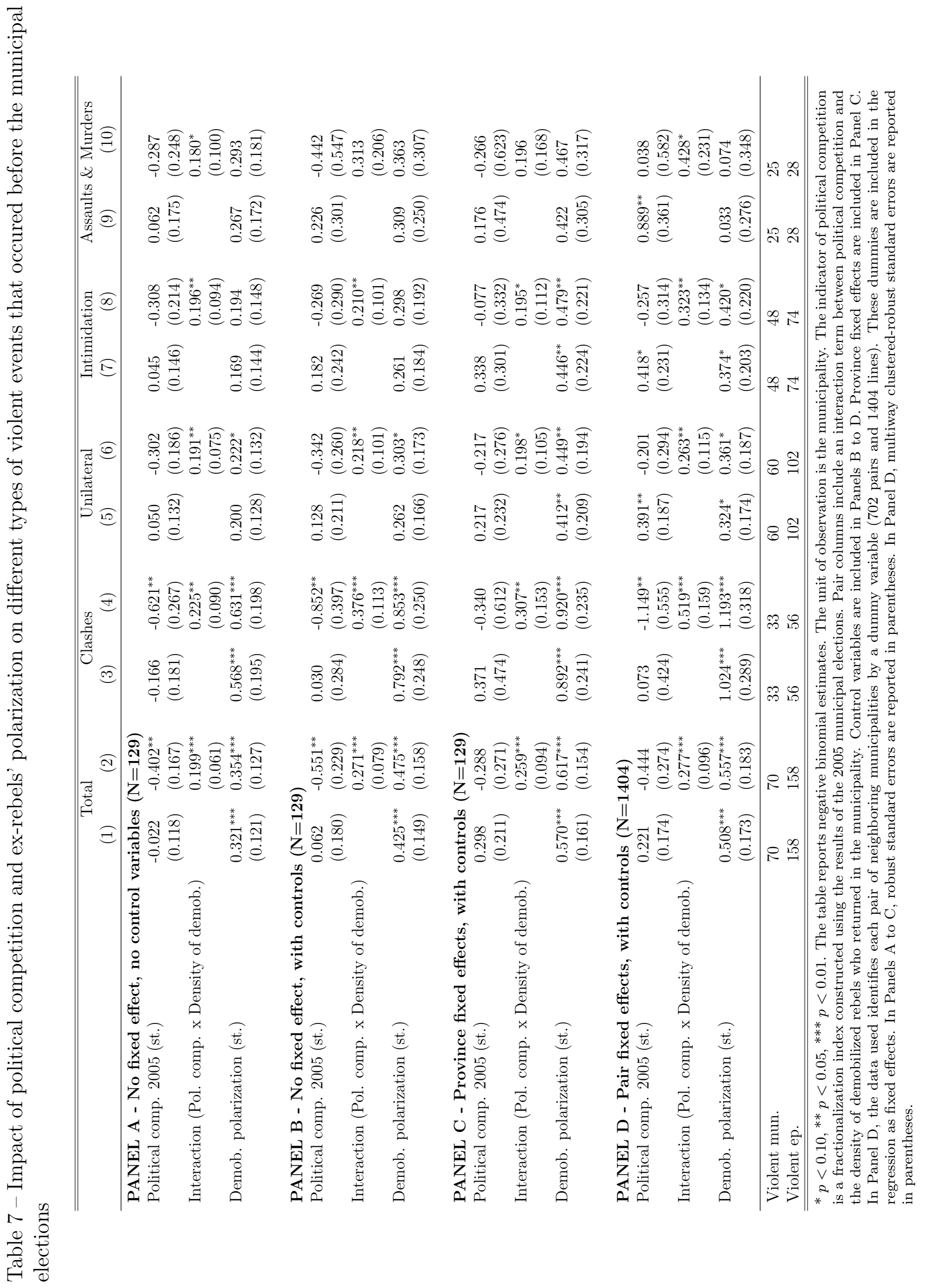


ent from zero. This coefficient is larger than the coefficients associated with ex-rebels' polarization when the aggregated measure of electoral violence is considered. A onestandard-deviation increase in ex-rebels' polarization results in a 144 to $230 \%$ increase in the predicted numbers of clashes, depending on which specification is considered. The interaction between political competition and the number of demobilized rebels per 1,000 inhabitants is also positive and significant. Clashes between political actors are more likely to occur when political competition is tight and in the presence of numerous demobilized combatants (marginal effects are shown in Figure 8 in Appendix E).

Columns (5) and (6) of Table 7 report the results for unilateral violence. The coefficient of the interaction term is positive and highly significant, suggesting that political competition and the density of demobilized combatants are complementary factors of violence (marginal effects are shown in Figure 9 in Appendix E). As predicted by the model, the correlation between ex-rebels' polarization and unilateral violence is positive, but lower than for bilateral violence ( $\mathrm{p}$-values one tailed test $=0.06$ with province fixed effects and 0.01 with pair fixed effects). A one-standard-deviation increase in ex-rebels' polarization increases the likelihood of unilateral violence by 38 to $57 \%$, depending on which specification is considered.

Results for intimidation are presented in columns (7) and (8). As predicted by the model, the interaction between political competition and the density of demobilized combatants is positively associated with intimidation (marginal effects are shown in Figure 10 in Appendix E). The coefficient associated with ex-rebels' polarization is also positive and significant, but the coefficient is lower than for clashes.

Columns (9) and (10) report the results for assaults and murders. As for other categories, the coefficient of the interaction variable between political competition and the density of violent supporters is positive (marginal effects are shown in Figure 11 in Appendix E). This interaction term is statistically significant in panel A and panel D. The regressions with pair fixed effects offer some suggestive evidence that polarization between ex-rebels might not be important for assaults and murders. However, this result is not 
very robust. The coefficients of polarization between demobilized combatants are not statistically different from 0 , nor are they significantly lower than the coefficient of ex-rebels' polarization in the regression on "intimidation". These results suggest that polarization between demobilized combatants may not play a significant role for assaults and murders. It is however unclear if this type of violence can be considered as "high-cost" unilateral violence, as hypothesized in the model.

\section{Robustness}

This section shows that empirical results are quite robust, suggesting that they are unlikely to be driven by omitted variables, by reverse causality, by the functional form of variables of interest, or by spatial dependence. The only exception is the coefficient of ex-rebels' polarization in the regression on "assaults and murders", which is not very stable. Falsification tests suggest that pre-election violence is different from other types of violence and from fraud. The regression tables of these robustness exercises are reported in Appendix D.

\subsection{Omitted variables}

Omitted variables are unlikely to significantly bias the results. First, benchmark regressions already include some important control variables that are expected to have an impact on electoral violence and be correlated with variables of interest (e.g. violence during the civil war, ethnic distribution, population size, night light luminosity, geographic variables).

The coefficients associated with political competition are unlikely to be biased by omitted variables. To induce a bias, an unobserved variable $A$ would need to impact electoral violence, and influence votes via a separate channel such as to alter political competition in a non-random way. Benchmark regressions include the proportion of votes obtained by major parties in 2005 in order to indirectly control for unobserved variables like $A$. Controlling for the share of votes obtained by each party also indirectly controls for 
unobserved variables affecting voters' preferences. Adding a dummy identifying provincial capitals does not significantly affect the coefficients of interest, showing that the results are not driven by strategic municipalities (Panel B, Table A.2).

Similarly, results associated with ex-rebels' polarization are unlikely to be biased by omitted variables. Two types of unobserved factors could generate a spurious correlation between ex-rebels' polarization and electoral violence. First, results could be biased if some unobserved variables $B$ affected electoral violence, and impacted the size of demobilized rebel groups through a separate channel, thereby affecting ex-rebels' polarization in a non-random way. In this case, the coefficient associated with ex-rebels' polarization would partly capture the impact of unobserved factors $B$. In order to indirectly control for these factors, measures of the relative size of demobilized rebel groups are included in the vector of controls of Table A.3. This inclusion also indirectly controls for unobserved variables affecting the location of ex-combatants. The inclusion of these controls does not significantly affect the results, except for the regressions on "assaults and murders" (the coefficient of ex-rebel polarization is much larger and significantly different from 0 with these controls). Second, coefficients associated with ex-rebels' polarization could be biased by some unobserved factors $C$ which directly affected electoral violence and influenced the place of resettlement of demobilized combatants after the conflict. This type of bias is expected to be marginal. A large majority (83\%) of demobilized rebels returned to their municipality of origin. Among those who did not return to their municipality of origin, $52 \%$ resettled in the capital Bujumbura Mairie. Excluding Bujumbura Marie from the sample does not significantly affect the coefficients associated with ex-rebels' polarization (Panel C, Table A.2). Using information on the origin of demobilized rebels instead of their place of return does not significantly affect the results (Panel D, Table A.2).

Results related to the interaction term do not change significantly if regressions include supplementary interaction terms between political competition and variables highly correlated with the density of demobilization (Table A.13). Unfortunately, considering a triple interaction between political competition, the density of demobilized rebels, and ex- 
rebels' polarization leads to results which are mostly insignificant and difficult to interpret (Table A.14), possibly because of reduced statistical power.

The results are also robust to the use of different fixed effect strategies to control for unobserved variation that is geographically correlated. Similar conclusions are obtained without fixed effect, with province fixed effects, with pair fixed effects, with fixed effects identifying neighborhood of municipalities, or with pair fixed effects and randomly selected pairs of municipalities (Panel B, Table A.4).

Even if these various tests are reassuring, I cannot formally rule out that results are biased by unobserved causes of electoral violence that correlate with the degree of competition or with the degree of ex-rebel's polarization. The methods proposed by Altonji et al. (2005) and Oster (2017) can be used to estimate the relative influence of unobserved variables by analyzing how coefficients of interest are affected by the inclusion of control variables. The method compares the coefficients $\hat{\beta}_{R}$ obtained in a regression with a restricted set of controls, and the coefficients $\hat{\beta}_{F}$ obtained with the full set of controls. The ratio $\hat{\beta}_{F} /\left(\hat{\beta}_{R}-\hat{\beta}_{F}\right)$ measures how strong the selection on unobservables should be relative to the selection on observables to wipe away the estimated effect of the variable of interest (Bellows and Miguel 2009; Nunn and Wantchekon 2011). Regressions without controls are presented in the Panel A of Table 7 (restricted equation), regressions with controls are presented in the Panel B without fixed effect, and in Panels $\mathrm{C}$ and $\mathrm{D}$ with province and pair fixed effects respectively. The coefficients of political competition (in odd columns), of the interaction term, and of ex-rebels' polarization all increase when control variables are added to the regression, leading to negative ratios $\hat{\beta}_{F} /\left(\hat{\beta}_{R}-\hat{\beta}_{F}\right)$. Intuitively, controlling for more unobserved variables should result in the measurement of higher coefficients of interest. ${ }^{30}$ Benchmark estimates are therefore likely to be lower bounds.

In conclusion, the problem of omitted variables is likely to be marginal in this study.

\footnotetext{
${ }^{30}$ Similarly, all coefficients of interest but one increase when control variables and province fixed effects are considered. The interaction variable in the regression on intimidation is reduced from 0.196 without control variable to 0.195 with control variables and province fixed effects $(-0.51 \%$ only).
} 


\subsection{Reverse causality}

The results associated with political competition are unlikely to be driven by reverse causality as political competition is measured 5 years before the 2010 elections. This strategy to mitigate reverse causality may, however, be imperfect (Reed 2015). Results do not change significantly if the political competition index is constructed using the results of the 2010 elections (Panel B, Table A.5), or if, as recommended by Reed (2015), political competition in 2010 is instrumented with political competition in 2005 (Panel C, Table A.5). ${ }^{31}$ This indicates that the risk of reverse causality bias is marginal, even with 2010 data on political competition.

Similarly, the location of return of ex-combatants was measured long before the 2010 elections, implying that results related on the distribution of ex-rebels are not affected by reverse causality.

\subsection{Alternative functional forms}

The results are robust to changes in the functional forms of the dependent and explanatory variables. Given the count and overdispersed nature of electoral violence data, the econometric model was estimated using the negative binomial regression model. Similar results are obtained with the Poisson model (Panel B, Table A.6). Coefficients have the expected sign but less precisely measured with OLS (Panel C, Table A.6).

Results are also similar if the measures of pre-electoral violence are based on the 374

\footnotetext{
${ }^{31}$ Because I estimate a negative binomial regression model, the IV strategy is a control function approach, in which I include the residuals from the first stage and their squared value in the second stage (Hilbe 2011; Wooldridge 2010). The correlation between political competition in 2010 and political competition in 2005 is as high as 0.84 (F-test $=306)$, showing that the two variables capture the same dynamics and that the instrumentation is unlikely to be weak. This diagnosis is confirmed by F-tests on excluded instruments and Kleibergen-Paap F-tests. The exclusion restriction of the instrumental variable approach would be violated if (1) political fractionalization in 2005 is correlated with electoral violence in 2010 through a separate channel than political fractionalization in 2010 and (2) this channel is not captured by control variables and geographical fixed effects. To minimize this possibility, I control for the shares of municipal seats obtained by major parties in 2005. Political fractionalization is a nonlinear function of these shares. Controlling for these shares should capture most channels through which electoral results in 2005 affected electoral violence in 2010. For example, it would capture the fact that the CNDD-FDD-led government may have invested less in municipalities in which other parties obtained a high score in 2005, which in turn, may have increased the risk of violence in 2010 .
} 
events that took place before the last round of the electoral process, that is, before the local elections organized on the 7th of September 2010 (Panel D, Table A.6).

Alternative functional forms for political competition and ex-rebels' polarization yield similar results. Following Condition (1), political competition can also be measured by the difference in the percentage of votes obtained by the two most important parties in municipalities $^{32}$ (Panel B, Table A.7). Political competition seems to be better measured by an indicator of fractionalization than an indicator of polarization (Panels $\mathrm{C}$ and $\mathrm{D}$, Table A.7).

Similarly, the distribution of ex-rebels seems to be better captured by an indicator of polarization than an indicator of fractionalization (Panels B and C, Table A.8). Ex-rebels' polarization can be replaced by the $R Q$ index of Garcia-Montalvo and Reynal-Querol (2005b) without substantially affecting the results (Panel D, Table A.8).

Results do not change significantly when the indicator of ethnic fractionalization (Panel B, Table A.9), or when both indicators of ethnic distribution are excluded from the list of controls (Panel C, Table A.9). Controlling for the square of the share of Hutu living in each municipality does not significantly change the results, showing that the findings are not driven by higher order in ethnic distribution (Panel D, Table A.9).

Importantly, multicollinearity between political competition and ex-rebel's polarization is not an issue in this study, as the coefficient of correlation between these two variables is as low as 0.15 (Table A.1).

Finally, results are not significantly affected if the two main hypotheses are tested separately (Table A.10). The coefficients of control variables do not change significantly when variables of interest are removed from the regressions, suggesting that political competition and polarization between demobilized rebels are not the outcomes of control

\footnotetext{
${ }^{32}$ The theoretical model predicts that violence is more likely to emerge when the difference of vote shares exceed a certain threshold. To capture this threshold effect (non-linearity), the indicator is computed as the square of the difference of vote shares between the first and second most important parties in each municipalities: Political competition $=1-\left|v_{i}-v_{j}\right|^{2}$. The minus sign aims at facilitating the interpretation of results (political competition is low when the indicator approach 0 , and high when it is close to 1).
} 
variables in a causal chain.

\subsection{Spatial dependence}

The Moran's statistics associated with the aggregate measure of violence and with the measures of bilateral and unilateral violence are low and not significantly different from zero, showing that spatial correlation is unlikely to be an issue when studying these dependent variables (Table 5). Furthermore, geographical fixed effects should capture a large part of the spatial correlation in the dependent variables. Following Neumayer and Plümper (2010), I find that controlling for the average value of the dependent variable in neighboring municipalities does not significantly affect the results (Panel B, Table A.11). The Panel C of Table A.11 presents the results of OLS regressions with standard errors adjusted for spatial correlation (Conley 1999) (this method has not yet been adapted for the negative binomial regression model). While the use of OLS reduces the precision of a few coefficients, the adjustment of standard errors does not affect much the significance of the results.

\subsection{Falsification tests}

Is pre-election violence different? In order to answer this question, I tested whether political competition and the distribution of demobilized combatants are correlated (1) with post-election violence, (2) with the indicator measuring violence during the Burundian civil war (based on ACLED data), and (3) with a measure of electoral fraud during the 2010 elections (from the same source as the electoral violence data). Results, which must be taken as suggestive, indicate that pre-election violence is different. Violence after the 2010 municipal election in Burundi mainly occurred where pre-election violence occurred (Panel B, Table A.12). The coefficients of political competition and ex-rebels polarization are mostly insignificant, suggesting that these factors only affected post-election violence indirectly, through their impacts on pre-election violence. Political competition and exrebels polarization are not significantly correlated with violence during the Burundian civil war and electoral fraud (Panel C, Table A.12). 


\section{Discussion and Conclusion}

To conclude, I discuss the contributions of this article and highlight areas for future research.

This article contributes to the growing literature on the causes of electoral violence. Electoral violence is a catch-all term regrouping a wide variety of violent behavior committed before, during, or after elections by a multitude of actors (Matanock and Staniland 2018), from parties (Fearon 2011; Ellman and Wantchekon 2000) to insurgents (Condra et al. 2017), mafias (De Luca and De Feo 2017), militias (Acemoglu et al. 2013), gangs (Dercon and Gutiérrez-Romero 2012). Electoral malpractices not only affect election results (Getmansky and Zeitzoff 2014; Gould and Klor 2010), but also undermine governance (Collier and Hoeffler 2015; Chauvet and Collier 2009) and have dramatic consequences on civilian populations (Dupas and Robinson 2012; Steele 2011). Robinson and Torvik (2009) show that swing voters, rather than ideological voters, can be targeted by electoral violence if voting preferences are highly dispersed.

The present research advances this literature by studying under which conditions parties resort to pre-electoral violence. It proposes a new model of pre-electoral violence, which predicts that violence before elections emerges as a result of tight political competition between parties with similarly large numbers of violent supporters. An important contribution of the paper is to derive a new indicator of polarization, which is compared to the polarization index of Garcia-Montalvo and Reynal-Querol (2005b). Empirical results on the causes of electoral violence in Burundi in 2010 are consistent with these predictions. The external validity of the present analysis should be assessed in future research. The 2010 electoral process in Burundi took place amid great uncertainty and insecurity, only a few months after the end of a long civil war. Electoral competition was intense both at the local and national levels. In different settings, the role of violent supporters may be played by actors other than demobilized combatants (e.g. the army, mafias (De Luca and De Feo 2017), militias (Acemoglu et al. 2013), or gangs (Dercon and Gutiérrez-Romero 2012)). The predictions of existing models should be tested in different 
contexts, to determine the conditions under which the various and sometimes conflicting mechanisms apply. Future research could also examine empirically why parties sometimes decide to withdraw from elections, and explore theoretically when this strategy might be effective.

This paper also contributes to the literature on post-conflict recovery (Chen et al. 2008). The recent literature on past violence and political participation identifies a positive link between victimization and political participation (Bateson 2012). In Uganda, youth returning from abduction are more likely to vote and be community leaders (Blattman 2009). In Sierra Leone, victims of war violence are more likely to vote and participate in local politics (Bellows and Miguel 2009). At the macro-level, Matanock (2017) shows that the chances of conflict relapse are substantially reduced when peace agreements include "electoral participation provisions" mandating that ex-rebel groups compete alongside political parties in post-conflict elections. In contrast, the present study shows that the experience of past violence can also have detrimental effects on political participation. In our case study, the distribution of demobilized combatants is correlated with electoral violence in two ways. First, the total number of demobilized combatants who returned to a municipality interacts positively with political competition to favor the emergence of electoral violence. Second, the analysis shows that violence increases with high polarization between demobilized rebels. Demobilized combatants appear to be involved in electoral violence, despite having received large demobilization grants to facilitate their return to civilian life (D'Aoust et al. 2016; Gilligan et al. 2013). This paper therefore adds to the conflict trap literature, by showing that the transformation of rebel groups into political parties may foster violence in post-war democracies. Further research is needed to clarify the nature of the relationship between violent supporters and political parties, and to better understand the roles and motivations of violent supporters.

This article also provides guidance on how to improve prevention programs against electoral malpractices. Recent empirical evidence suggests several avenues for preventing electoral fraud and violence. Election monitoring by the international community appears to reduce irregularities where international observers operate (Ichino and Schündeln 2012; 
Hyde 2007). Fraud seems to be displaced to nearby electoral areas that are unmonitored (Ichino and Schündeln 2012). New monitoring technologies appear to be very effective at reducing aggregation fraud (Callen and Long 2014). Electoral violence can be effectively reduced and turnout increased by an anti-violence community campaign (Collier and Vicente 2013). More generally, political violence and corrupt behavior can be reduced by improving public service provision (Berman et al. 2011) and by enhancing political accountability (Ferraz and Finan 2011; Besley and Burgess 2002). The present article suggests that prevention efforts could be targeted at specific groups in places characterized by high political competition, numerous violent supporters, and high polarization between these. Assessing the impact of interventions targeted at demobilized rebels - and violent supporters in general - is much needed (Blattman and Annan 2016).

Finally, this paper calls for more research on the causes of instability in Burundi. The recent political turmoil which surrounded the 2015 electoral process in Burundi left more than a hundred people dead, and more than 200,000 people were forced to flee to neighboring countries, further fueling the already serious regional crisis. This dramatic situation is a sad illustration of the terrible consequences of electoral violence on the civilian population, and a strong reminder of the importance of understanding and preventing electoral violence.

\section{References}

Acemoglu, D., J. A. Robinson, and R. J. Santos (2013). The monopoly of violence: Evidence from Colombia. Journal of the European Economic Association 11 (suppl_1), $5-44$.

Altonji, J., T. Elder, and C. Taber (2005). Selection on Observed and Unobserved Variables : Assessing the Effectiveness of Catholic Schools. Journal of Political Economy 113(1), 151-184. 
Amatora Mu Mahoro (2010). Rapport final: Système de Monitoring des Principes Démocratiques et de Prévention de la Violence Électorale.

Bateson, R. (2012). Crime victimization and political participation. American Political Science Review 106(3), 570-587.

Bellows, J. and E. Miguel (2009). War and local collective action in Sierra Leone. Journal of Public Economics 93(11), 1144-1157.

Berman, E., J. N. Shapiro, and J. H. Felter (2011). Can hearts and minds be bought? The economics of counterinsurgency in Iraq. Journal of Political Economy 119(4), 766-819.

Besley, T. and R. Burgess (2002). The political economy of government responsiveness: Theory and evidence from India. The Quarterly Journal of Economics 117(4), 14151451.

Besley, T., T. Persson, and D. M. Sturm (2010). Political competition, policy and growth: theory and evidence from the US. The Review of Economic Studies 7r(4), 1329-1352.

Bhasin, T. and J. Gandhi (2013). Timing and targeting of state repression in authoritarian elections. Electoral Studies 32(4), 620-631.

Bishop, S. and A. Hoeffler (2014). Free and Fair Elections - A New Database. CSAE Working Papers 14.

Blattman, C. (2009, June). From violence to voting: War and political participation in Uganda. American Political Science Review 103(02), 231-247.

Blattman, C. and J. Annan (2016). Can employment reduce lawlessness and rebellion? A field experiment with high-risk men in a fragile state. American Political Science Review 110(1), 1-17.

Buhaug, H., S. Gates, and P. Lujala (2009). Geography, rebel capability, and the duration of civil conflict. Journal of Conflict Resolution 53(4), 544-569. 
Callen, M. and J. D. Long (2014). Institutional corruption and election fraud: Evidence from a field experiment in Afghanistan. The American Economic Review 105(1), 354381.

Chacón, M., J. A. Robinson, and R. Torvik (2011). When is democracy an equilibrium? theory and evidence from Colombia's la Violencia. Journal of Conflict Resolution 55 (3), 366-396.

Chaturvedi, A. (2005). Rigging Elections With Violence. Public Choice 125(1-2), 189202.

Chauvet, L. and P. Collier (2009). Elections and Economic Policy in Developing Countries. Economic Policy 24(59), 509-550.

Chen, S., N. V. Loayza, and M. Reynal-Querol (2008). The aftermath of civil war. The World Bank Economic Review 22(1), 63-85.

Collier, P. (2008). The bottom billion: Why the poorest countries are failing and what can be done about it. New York: Oxford University Press.

Collier, P. and A. Hoeffler (2004). Greed and Grievance in Civil War. Oxford Economic Papers 56(4), 563-595.

Collier, P. and A. Hoeffler (2015). Do elections matter for economic performance? Oxford Bulletin of Economics and Statistics 77(1), 1-21.

Collier, P. and P. Vicente (2012). Violence, Bribery, and Fraud: the Political Economy of Elections in Sub-Saharan Africa. Public Choice 153(1-2), 117-147.

Collier, P. and P. Vicente (2013). Votes and Violence: Evidence from a Field Experiment in Nigeria. The Economic Journal 124(February), 327-355.

Colombo, A., O. D'Aoust, and O. Sterck (2019). From rebellion to electoral violence: Evidence from burundi. Economic Development and Cultural Change 67(2), 333-368. 
Condra, L. N., J. D. Long, A. C. Shaver, and A. L. Wright (2017). The logic of insurgent electoral violence. Unpublished manuscript.

Conley, T. G. (1999). GMM estimation with cross sectional dependence. Journal of Econometrics 92(June 1998), 1-45.

D'Aoust, O., O. Sterck, and P. Verwimp (2016). Who benefited from Burundi's demobilization program? The World Bank Economic Review, lhw033.

Daxecker, U. E. (2012). The cost of exposing cheating: International election monitoring, fraud, and post-election violence in africa. Journal of Peace Research 49(4), 503-516.

De Luca, G. D. and G. De Feo (2017). Mafia in the ballot box. American Economic Journal: Economic Policy 9(3), 134-167.

Dercon, S. and R. Gutiérrez-Romero (2012). Triggers and Characteristics of the 2007 Kenyan Electoral Violence. World Development 40(4), 731-744.

Dupas, P. and J. Robinson (2010, May). Coping with Political Instability: Micro Evidence from Kenya's 2007 Election Crisis. American Economic Review 100(2), 120-124.

Dupas, P. and J. Robinson (2012, November). The (hidden) costs of political instability: Evidence from Kenya's 2007 election crisis. Journal of Development Economics 99(2), $314-329$.

Ellman, M. and L. Wantchekon (2000). Electoral Competition under the Threat of Political Unrest. The Quarterly journal of economics 115(2), 499-531.

Esteban, B. J., L. Mayoral, and D. Ray (2012a). Ethnicity and Conflict : An Empirical Study. American Economic Review 102(4), 1310-1342.

Esteban, J., L. Mayoral, and D. Ray (2012b). Ethnicity and conflict: Theory and facts. science 336(6083), 858-865.

Esteban, J. and D. Ray (1999). Conflict and distribution. Journal of Economic Theory $87(2), 379-415$. 
Esteban, J. and D. Ray (2011). Linking Conflict to Inequality and Polarization. American Economic Review 101(4), 1345-1374.

Fearon, J. D. (2011). Self-enforcing democracy. The Quarterly Journal of Economics 126(4), 1661-1708.

Ferraz, C. and F. Finan (2011). Electoral accountability and corruption: Evidence from the audits of local governments. The American Economic Review 101(4), 1274-1311.

Garcia-Montalvo, J. and M. Reynal-Querol (2005a, April). Ethnic diversity and economic development. Journal of Development Economics 76(2), 293-323.

Garcia-Montalvo, J. and M. Reynal-Querol (2005b). Ethnic Polarization, Potential Conflict and Civil Wars. American Economic Review 95(3), 796-816.

Getmansky, A. and T. Zeitzoff (2014). Terrorism and voting: The effect of rocket threat on voting in Israeli elections. American Political Science Review 108(3), 588-604.

Gilligan, M., E. Mvukiyehe, and C. Samii (2013). Reintegrating rebels into civilian life: Quasi-experimental evidence from Burundi. Journal of Conflict Resolution 57(4), 598626.

Gleditsch, N. P. et al. (2012). Whither the weather? Climate change and conflict. Journal of Peace Research 49(1), 3-9.

Goldstein, M. and C. Udry (2008). The profits of power : Land rights and agricultural investment in Ghana. Journal of Political Economy 116(6), 981-1022.

Gould, E. D. and E. F. Klor (2010). Does terrorism work? The Quarterly Journal of Economics 125(4), 1459-1510.

Hafner-Burton, E. M., S. D. Hyde, and R. S. Jablonski (2016). Surviving elections: Election violence, incumbent victory and post-election repercussions. British Journal of Political Science, 1-30. 
Henderson, J. V., T. Squires, A. Storeygard, and D. Weil (2018). The global distribution of economic activity: Nature, history, and the role of trade. The Quarterly Journal of Economics 133(1), 357-406.

Hilbe, J. (2011). Negative binomial regression. Cambridge, USA: Cambridge University Press.

Hsiang, S. M., M. Burke, and E. Miguel (2013). Quantifying the influence of climate on human conflict. Science 341(6151), 1235367.

Huillery, E. (2009). History Matters: The Long-Term Impact of Colonial Public Investments in French West Africa. American Economic Journal: Applied Economics 1(2), $176-215$.

Human Rights Watch (2010). "we'll tie you up and shoot you". lack of accountability for political violence in Burundi.

Hyde, S. D. (2007). The observer effect in international politics: Evidence from a natural experiment. World Politics 60(1), 37-63.

ICG (2011). Burundi: From Electoral boycott to Political Impasse. International Crisis Group Report 169.

Ichino, N. and M. Schündeln (2012). Deterring or displacing electoral irregularities? spillover effects of observers in a randomized field experiment in Ghana. The Journal of Politics 74(1), 292-307.

IFES (2010). International Foundation for Electoral Systems.

Mares, I. and L. Young (2016). Buying, expropriating, and stealing votes. Annual Review of Political Science 19, 267-288.

Matanock, A. M. (2017). Bullets for ballots: Electoral participation provisions and enduring peace after civil conflict. International Security 41(4), 93-132. 
Matanock, A. M. and P. Staniland (2018). How and why armed groups participate in elections. Perspectives on Politics 16(3), 710-727.

Neumayer, E. and T. Plümper (2010). Galton's Problem and Contagion in International Terrorism along Civilizational Lines. Conflict Management and Peace Science 27(4), $308-325$.

Nunn, N. and L. Wantchekon (2011). The slave trade and the origins of mistrust in Africa. American Economic Review 101(7), 3221-3252.

Oster, E. (2017). Unobservable selection and coefficient stability: Theory and evidence. Journal of Business E Economic Statistics, 1-18.

Palmans, E. (2012). Burundi's 2010 elections: Democracy and peace at risk. European Centre for Electoral Support, 219.

Reed, W. R. (2015). On the practice of lagging variables to avoid simultaneity. Oxford Bulletin of Economics and Statistics 7r7(6), 897-905.

Robinson, J. and R. Torvik (2009). The Real Swing Voter's Curse. American Economic Review 99(2), 310-315.

Skaperdas, S. and B. Grofman (1995). Modeling negative campaigning. American Political Science Review 89(1), 49-61.

Spolaore, E. and R. Wacziarg (2016). War and relatedness. Review of Economics and Statistics 98(5), 925-939.

Steele, A. (2011). Electing displacement: Political cleansing in Apartadó, Colombia. Journal of Conflict Resolution 55(3), 423-445.

Vandeginste, S. (2011). Power-sharing as a fragile safety valve in times of electoral turmoil: the costs and benefits of Burundi's 2010 elections. The Journal of Modern African Studies 49(2), 315-335. 
Wooldridge, J. (2010). Econometric Analysis of Cross Section and Panel Data. MIT Press Books. Cambridge, USA: MIT Press (2nd edition). 


\section{Appendix (for online publication)}

\section{A Mathematical Appendix}

\section{A.1 Unilateral violence}

Without loss of generality, let us assume that $v_{1}>v_{2}$. In this case, violence will only emerge if party 2 can win the elections by making a violent move, that is, if $v_{2}+\delta>0.5$.

If this condition is satisfied, the dynamic game is represented in Figure 7. Two cases should be distinguished: both parties may engage in violence, or party 2 only (the electorally weakest party) may engage in violence.

First, both parties may try to make a violent move. The problem is solved by backward induction. In the second stage, violence is the unique Nash equilibrium if the following conditions are satisfied.

$$
\left\{\begin{array}{l}
q\left(h_{2}\right) B-C>0 \\
{\left[1-q\left(h_{2}\right)\left(1-q\left(h_{1}\right)\right)\right] B-C-q\left(h_{2}\right) D>\left(1-q\left(h_{2}\right)\right) B-q\left(h_{2}\right) D} \\
q\left(h_{2}\right)\left(1-q\left(h_{1}\right)\right) B-C-q\left(h_{1}\right) D>-q\left(h_{1}\right) D
\end{array}\right.
$$

In the first stage, violence is the unique Nash equilibrium if:

$$
\left\{\begin{array}{l}
{\left[1-q\left(h_{2}\right)\left(1-q\left(h_{1}\right)\right)\right] B-C-q\left(h_{2}\right) D>0} \\
q\left(h_{2}\right)\left(1-q\left(h_{1}\right)\right) B-C-q\left(h_{1}\right) D>0
\end{array}\right.
$$

These five conditions can be rewritten:

$$
\left\{\begin{array}{l}
B q\left(h_{1}\right) q\left(h_{2}\right)>C \\
B-C-q\left(h_{2}\right) D>B\left(1-q\left(h_{1}\right)\right) q\left(h_{2}\right)>C+q\left(h_{1}\right) D
\end{array}\right.
$$

Both parties engaging in unilateral violence is the unique sub-game perfect Nash Equilibrium if these conditions are satisfied.

Second, only party 2 engages in violence if "political campaigning/violent campaigning" is the unique sub-game perfect Nash equilibrium. This will be the case in the second 
stage if:

$$
\left\{\begin{array}{l}
q\left(h_{2}\right) B-C>0 \\
{\left[1-q\left(h_{2}\right)\left(1-q\left(h_{1}\right)\right)\right] B-C-q\left(h_{2}\right) D<B\left(1-q\left(h_{2}\right)\right)-q\left(h_{2}\right) D}
\end{array}\right.
$$

In the first stage, only party 2 engages in violence if:

$$
\left\{\begin{array}{l}
q\left(h_{2}\right) B-C>0 \\
B\left(1-q\left(h_{2}\right)\right)-q\left(h_{2}\right) D>0
\end{array}\right.
$$

Altogether, these four conditions can be rewritten $B /(B+D)>q\left(h_{2}\right)>C / B>$ $q\left(h_{1}\right) q\left(h_{2}\right)$.

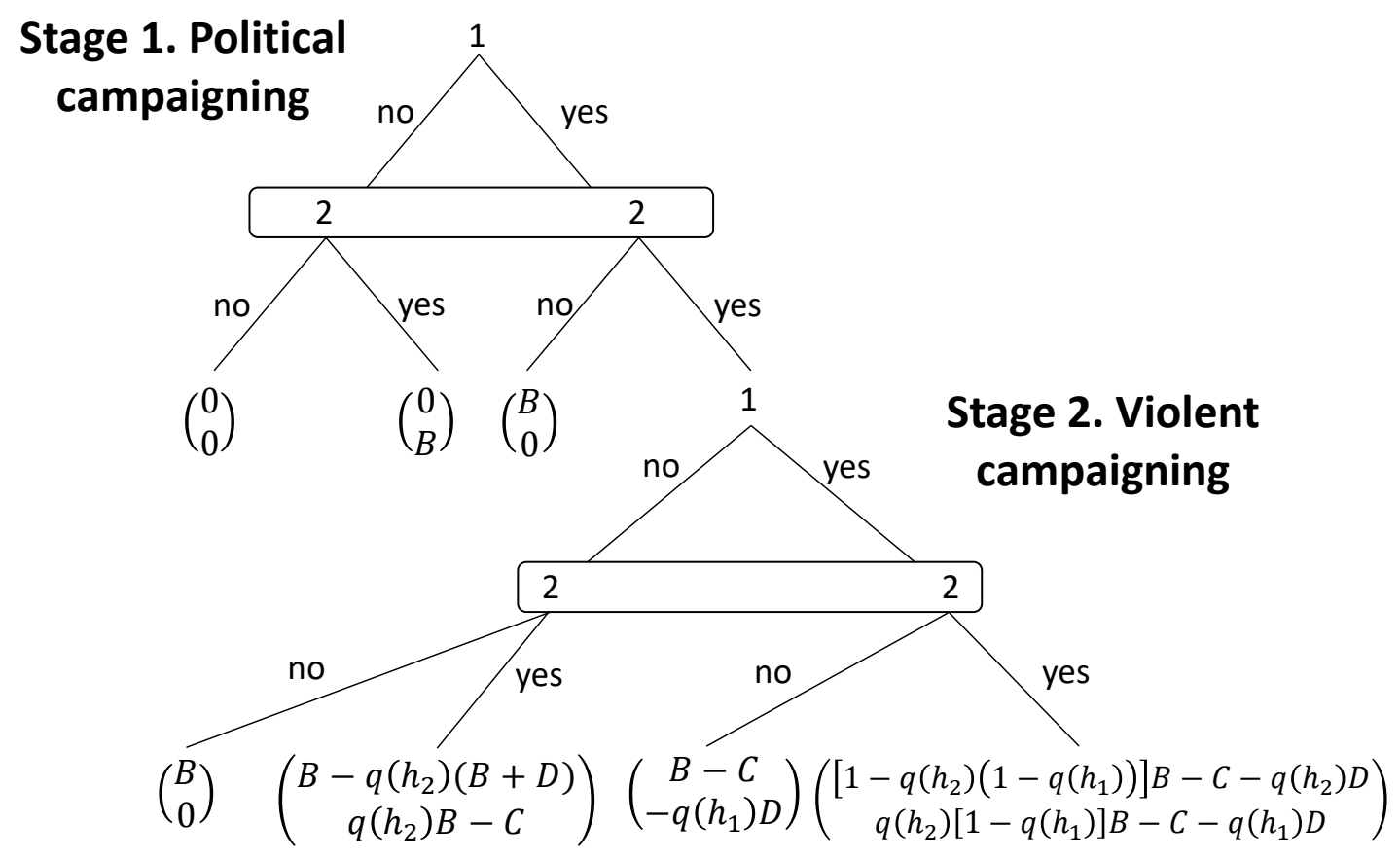

Figure 7 - Unilateral violence: pay-offs of the dynamic game

\section{B Extension to $N>2$ parties}

This section examines how Propositions 1 and 2 are affected if the model is extended to $N$ parties. As explained by Esteban and Ray (1999), "in general, the conflict distribution relationship is nonlinear and surprisingly complex", implying that simplifying 
assumptions are usually needed to solve models with $N>2$ players (Garcia-Montalvo and Reynal-Querol 2005a). With these limitations in mind, this section discusses the simpler case of bilateral violence, sticking to the same hypotheses as the $N=2$ case to the largest possible extent. I examine in turn how Conditions (1) and (2) are changed in the presence of more than two parties.

If bilateral violence emerges, the party winning the violent contest gets $\delta\left(h_{1}+\ldots+h_{N}\right)$ more votes, while all other parties lose $\delta\left(h_{1}+\ldots+h_{N}\right)$ votes. ${ }^{33}$ The probability that party $i$ wins a violent contest is determined by a function $Q\left(h_{i}, \sum_{j \in \Omega} h_{j}\right)$ where $\Omega$ is the set of other parties choosing to engage in violence. This probability is increasing in $h_{i}$ and decreasing in $h_{j} \forall j \in \Omega$. An example of functional form is the Tullock contest success function $Q\left(h_{i}, h_{j}\right)=h_{i} /\left(h_{i}+\sum_{j \in \Omega} h_{j}\right)$.

As before, party $i$ only engages in violence if (1) it expects to win the election in case of successful violent contest, that is, if $v_{i}+\delta\left(h_{1}+\ldots+h_{N}\right)>v_{j}-\delta\left(h_{1}+\ldots+h_{N}\right) \forall j$ and (2) it expects to lose the election if it does not respond to violence, that is, if $\exists j$ $v_{i}-\delta\left(h_{1}+\ldots+h_{N}\right)<v_{j}+\delta\left(h_{1}+\ldots+h_{N}\right)$. A necessary condition for violence to emerge is: $\exists i, j$ such $\left|v_{i}-v_{j}\right|<2 \delta\left(h_{1}+\ldots+h_{N}\right)$ and $v_{k}+\delta\left(h_{1}+\ldots+h_{N}\right)>v_{l}-\delta\left(h_{1}+\ldots+h_{N}\right)$ for $k=i, j$ and $\forall l$. In words, political competition should be tight between parties that engage in violence. The higher the number of parties for which this condition is satisfied, the higher the likelihood that at least two parties want to engage in violence. Therefore, political competition is expected to be best captured by an index of fractionalization between political parties rather than an indicator of political polarization.

Condition (2) is modified in the presence of multiple parties. Without loss of generality, let us assume $v_{i}>v_{j} \forall j$. In this case, violence is a dominant strategy for player $j$ if $B Q\left(h_{j}, \sum_{k \in \Omega} h_{k}\right)-C-D\left(1-Q\left(h_{j}, \sum_{k \in \Omega} h_{k}\right)\right)>0$. The left-hand side of this inequality is a decreasing function of the number of parties which decide to engage in violence. The party $i$ reacts by also engaging in violence if $B Q\left(h_{i}, \sum_{k \in \Omega} h_{k}\right)-C-D(1-$

\footnotetext{
${ }^{33}$ The total number of votes is then lower than 1 if $N>2$, which is consistent with the hypothesis that some voters abstain from voting when elections turn violent (Chaturvedi 2005; Collier and Vicente 2012).
} 
$\left.Q\left(h_{i}, \sum_{k \in \Omega} h_{k}\right)\right)>0$. There may be many different sets of parties $\Omega$ for which at least two parties decide to engage in violence, making this problem complex to solve. Two specific cases enlighten the main mechanisms at play.

Case 1 We follow Garcia-Montalvo and Reynal-Querol (2005a) by assuming that parties have the same numbers of violent supporters. In this case, the probability that a party wins the violent contest is given by $1 / N$. Bilateral violence is a dominant strategy for parties if: $B Q\left(h_{i}, n h_{i}\right)-C-D\left(1-Q\left(h_{i}, n h_{i}\right)>0\right.$. This inequality can be rewritten:

$$
1 / N>\frac{C+D}{B+D}
$$

The left-hand side of this inequality is a decreasing function of the number of parties, implying that violence is "more likely" to occur in the presence of only two parties of similar size. In this scenario, it is easy to show that inequality (3) is equivalent to (16):

$$
\begin{aligned}
& P_{S} \equiv 1-\sum_{k=1}^{N} \pi_{k}\left|\frac{0.5-\pi_{k}}{0.5}\right|>2 \frac{C+D}{B+D} \\
& \Leftrightarrow 1-N\left(\frac{1}{N}\left|\frac{0.5-1 / N}{0.5}\right|\right)>2 \frac{C+D}{B+D} \\
& \Leftrightarrow 1 / N>\frac{C+D}{B+D} .
\end{aligned}
$$

Polarization between violent supporters rather their fractionalization is what triggers bilateral violence.

Case 2 We assume that $N>2$ is fixed, that $n$ parties have a positive a number of violent supporters equal to $h_{n}$, and that $N-n$ parties have no violent supporters. In this case, parties with violent supporters have a probability $1 / n$ to win a bilateral contest, while parties with no violent supporters have no chance to win. Bilateral violence is a dominant strategy for parties with violent supporters if: 


$$
1 / n>\frac{C+D}{B+D}
$$

As the left-hand side of this inequality is decreasing with $n$, the incentive to engage in bilateral violence is higher in the presence of fewer groups with violent supporters. Again, what matters is the polarization between violent supporters rather than their fractionalization. It is easy to show that inequality (3) is equivalent to (17) in this scenario.

Robustness The predictions that political fractionalization and polarization between violent supporters are not robust to changes in the assumptions of the model.

For example, Esteban and Ray (2011) and Esteban et al. (2012b) show that fractionalization is what matters when the payoff from violence is private (such as looted resources), mainly because group size dilutes individual benefits. By contrast, polarization is key when the payoff from violence is public and hence undiluted by one's own group size. In the present model, parties decide to engage in violence or not in the second stage of the game. The potential net payoff of violence $(B-C)$ is a public good accessible to all members of the winning party, which leads to the result that it is the polarization between violent supporters which matter, and not their fractionalization. Assuming a private payoff would lead to a different prediction.

The polarization versus fractionalization debate also depends on the functional form of the contest success function. The Tullock contest success function leads to the conclusion that polarization matters more than fractionalization, simply because the likelihood of winning the contest decreases with the number of groups (assuming they are of similar size). Different functions would lead to different predictions. For example, in the first stage of game, political polarization is key if one assume that a party needs at least $50 \%$ of the votes to win the election. By contrast, fractionalization is what matters if the party with most votes wins the election (even if it does not reach $50 \%$ of votes). 
Finally, whether polarization or fractionalization matters depends on the correlation between parties' expected score without violence $v_{i}$ and parties' number of violent supporters $h_{i}$. If these two quantities are highly correlated, then the same type of indicator will matter for both political competition and for the distribution of violent supporters. If the two quantities are not correlated, as implicitly assumed in this appendix, different indicators might be adequate for political competition and for the distribution of violent supporters.

Because different assumptions lead to different predictions, and because the competing assumptions are all realistic, the fractionalization versus polarization debate is mainly an empirical question. 
C Correlation table 


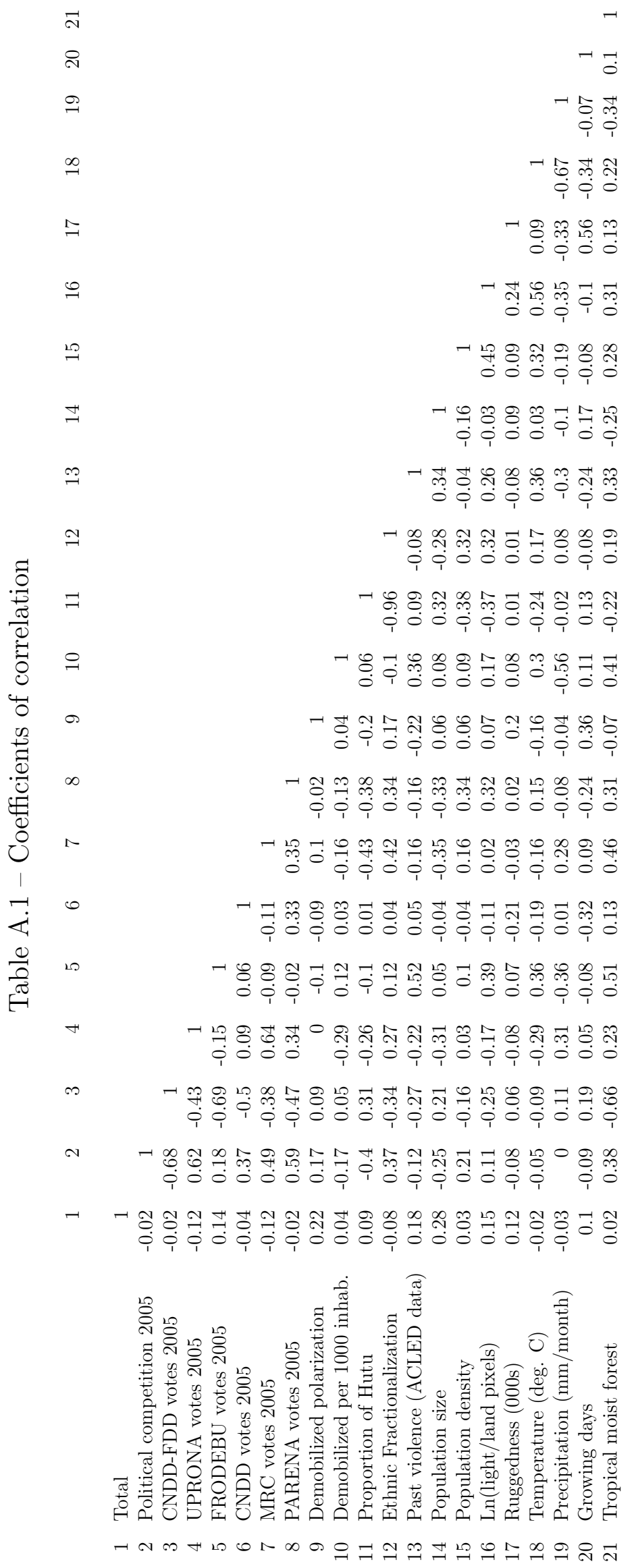


D Robustness 


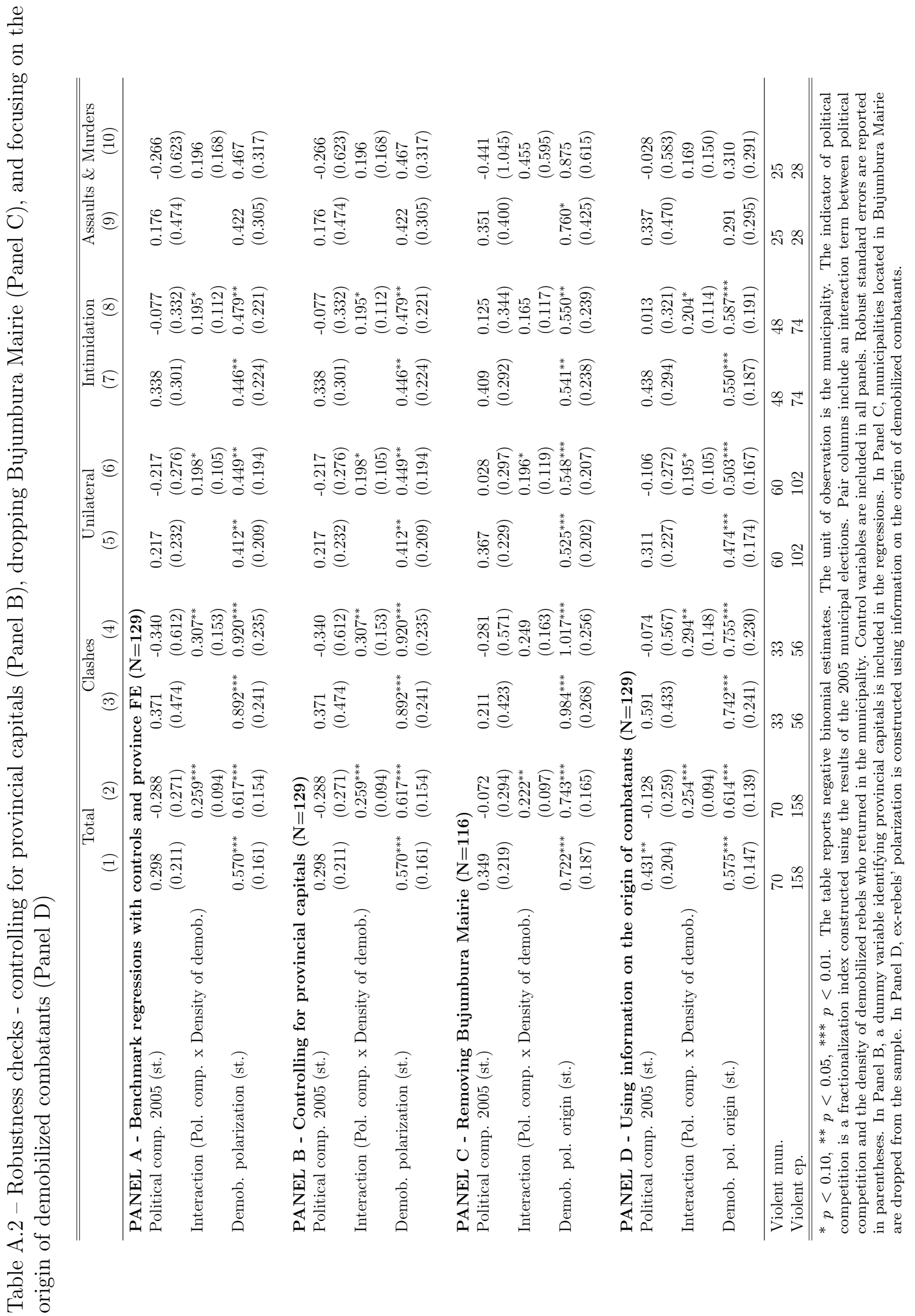




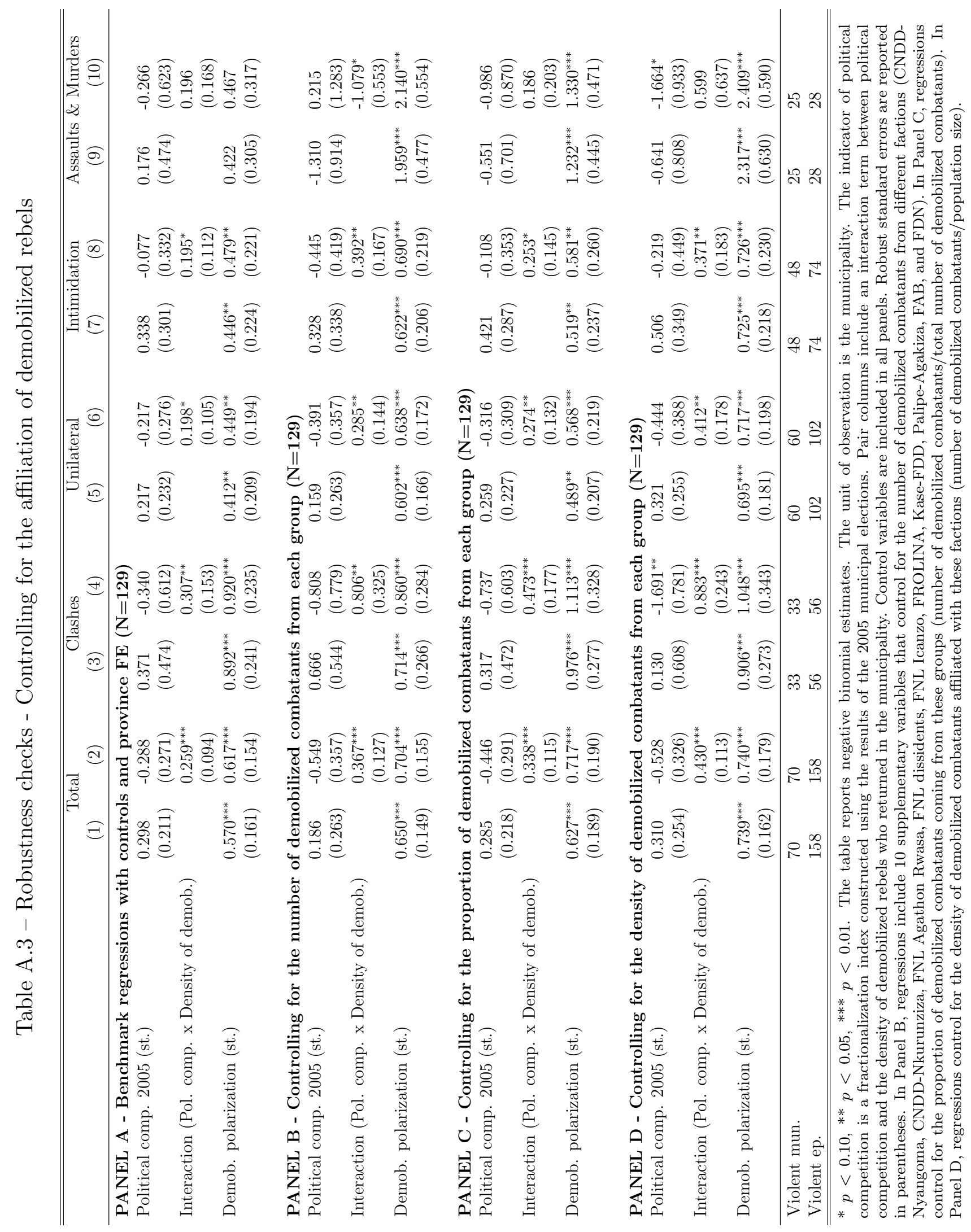




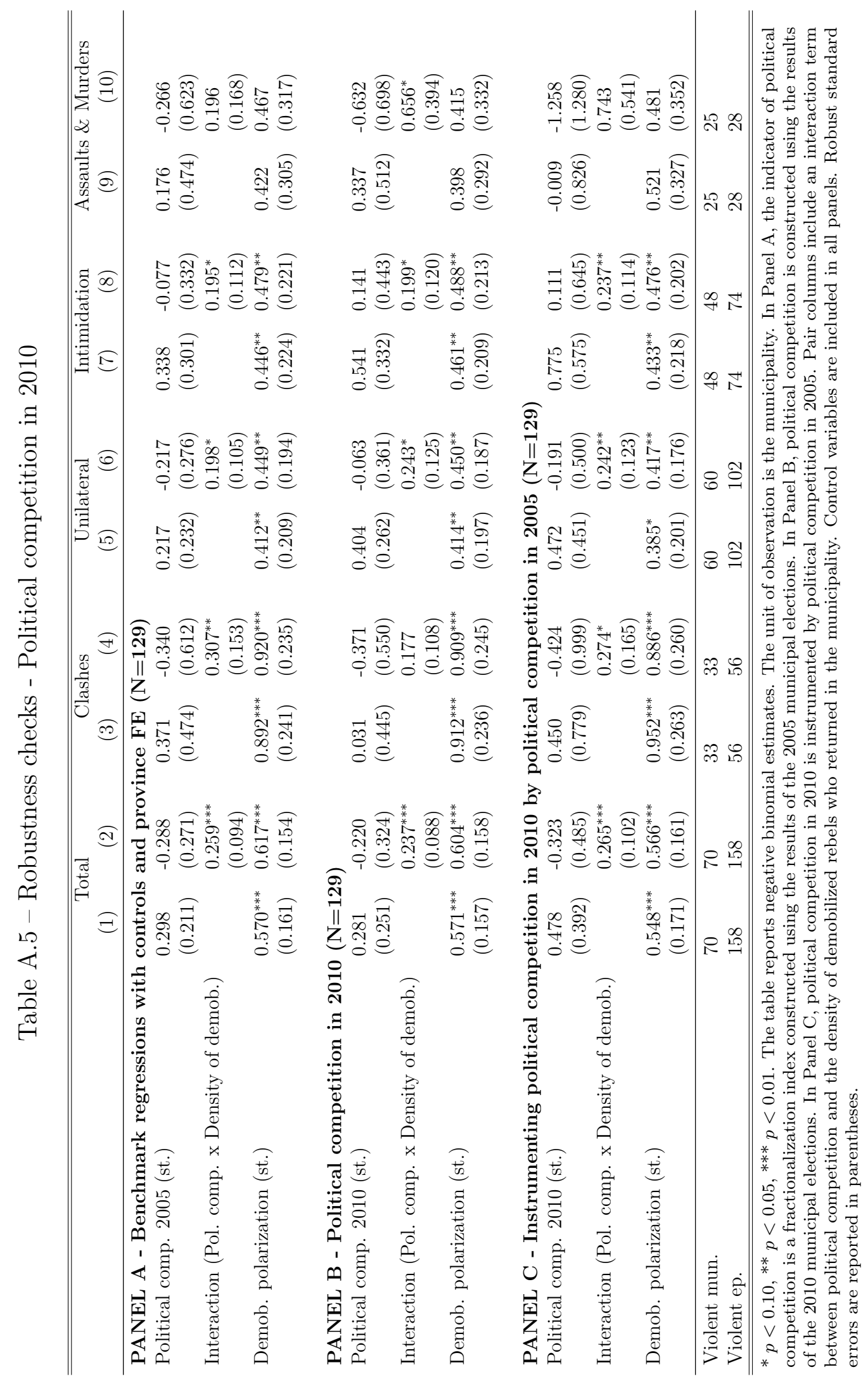




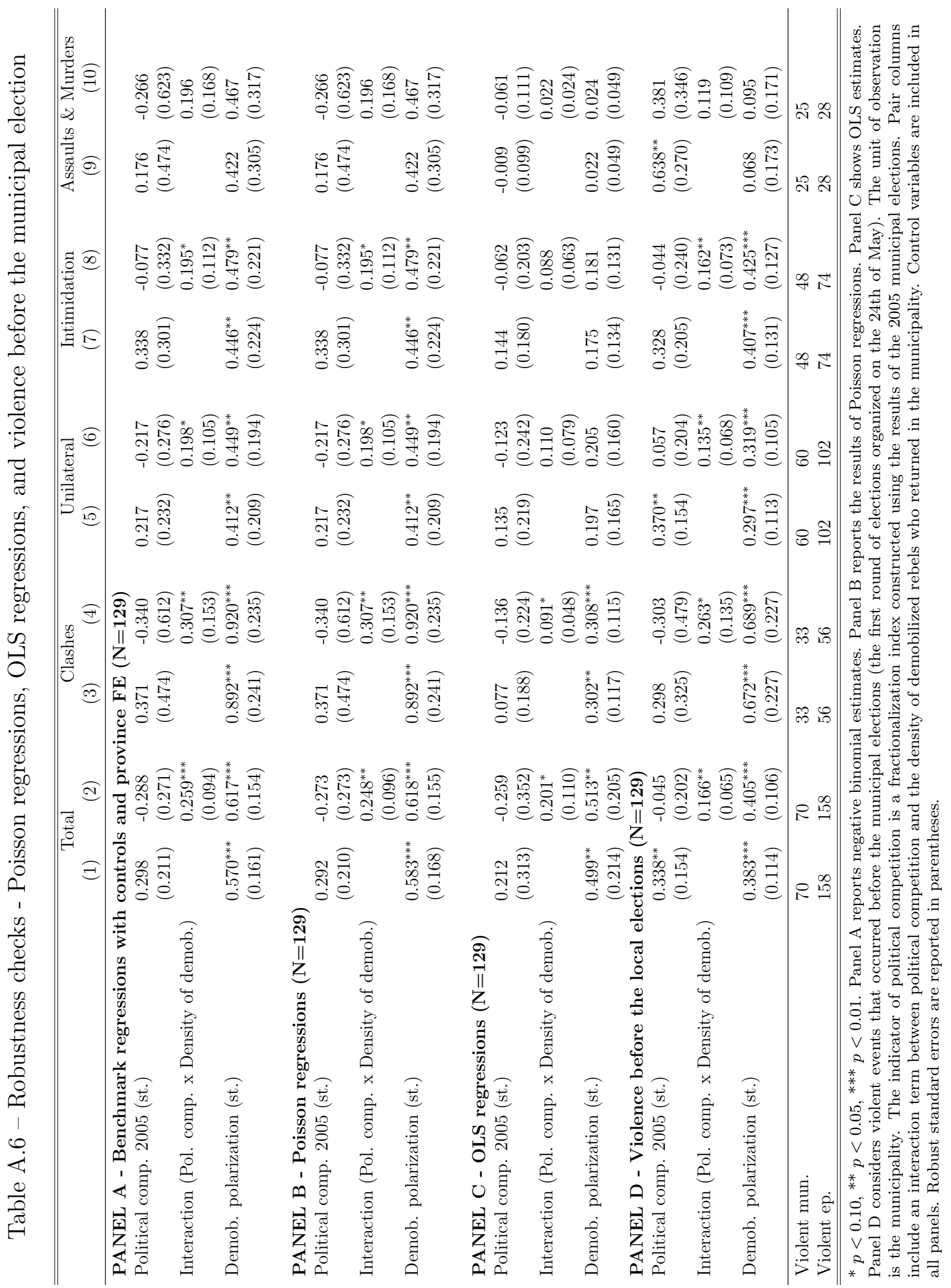




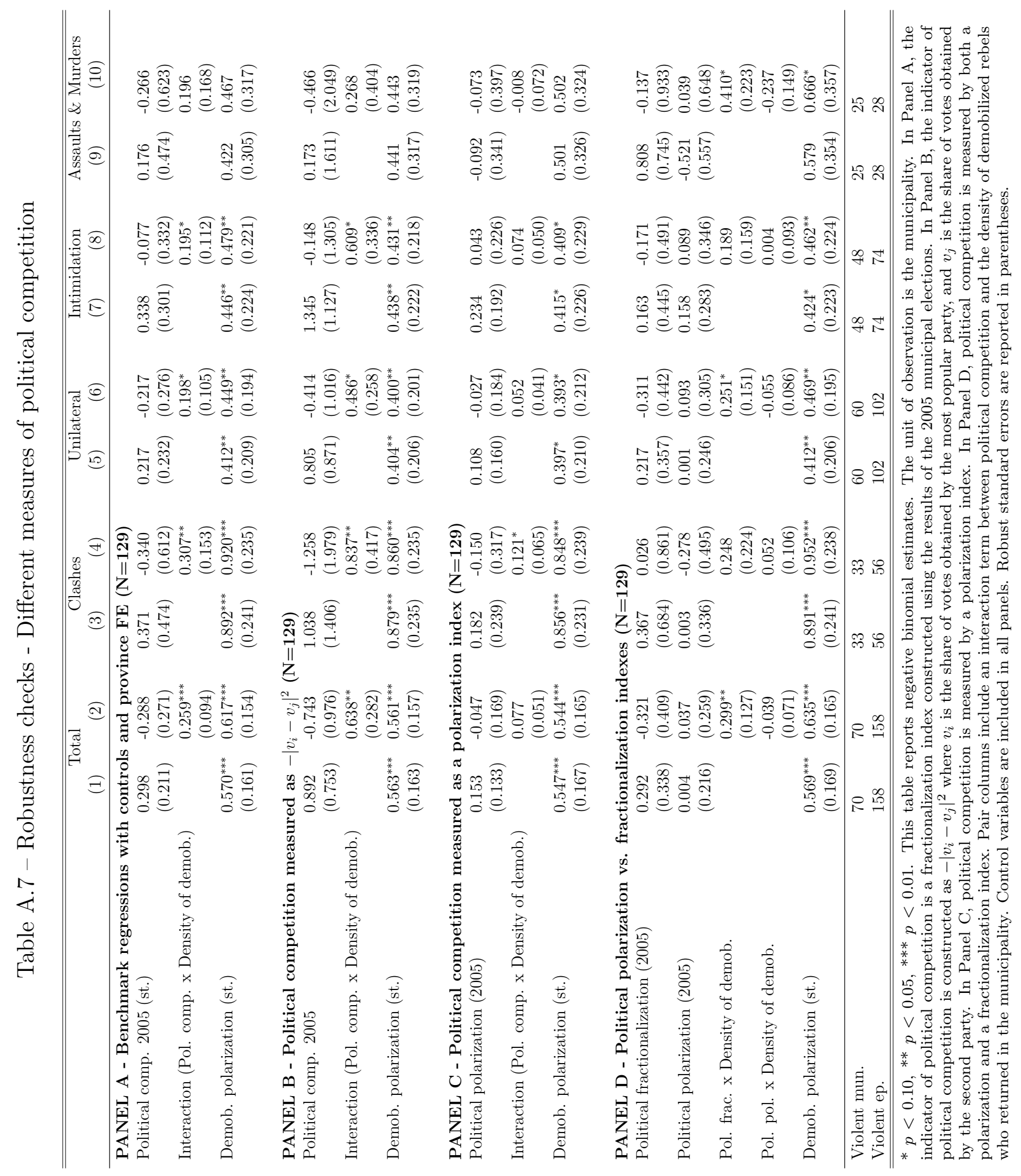




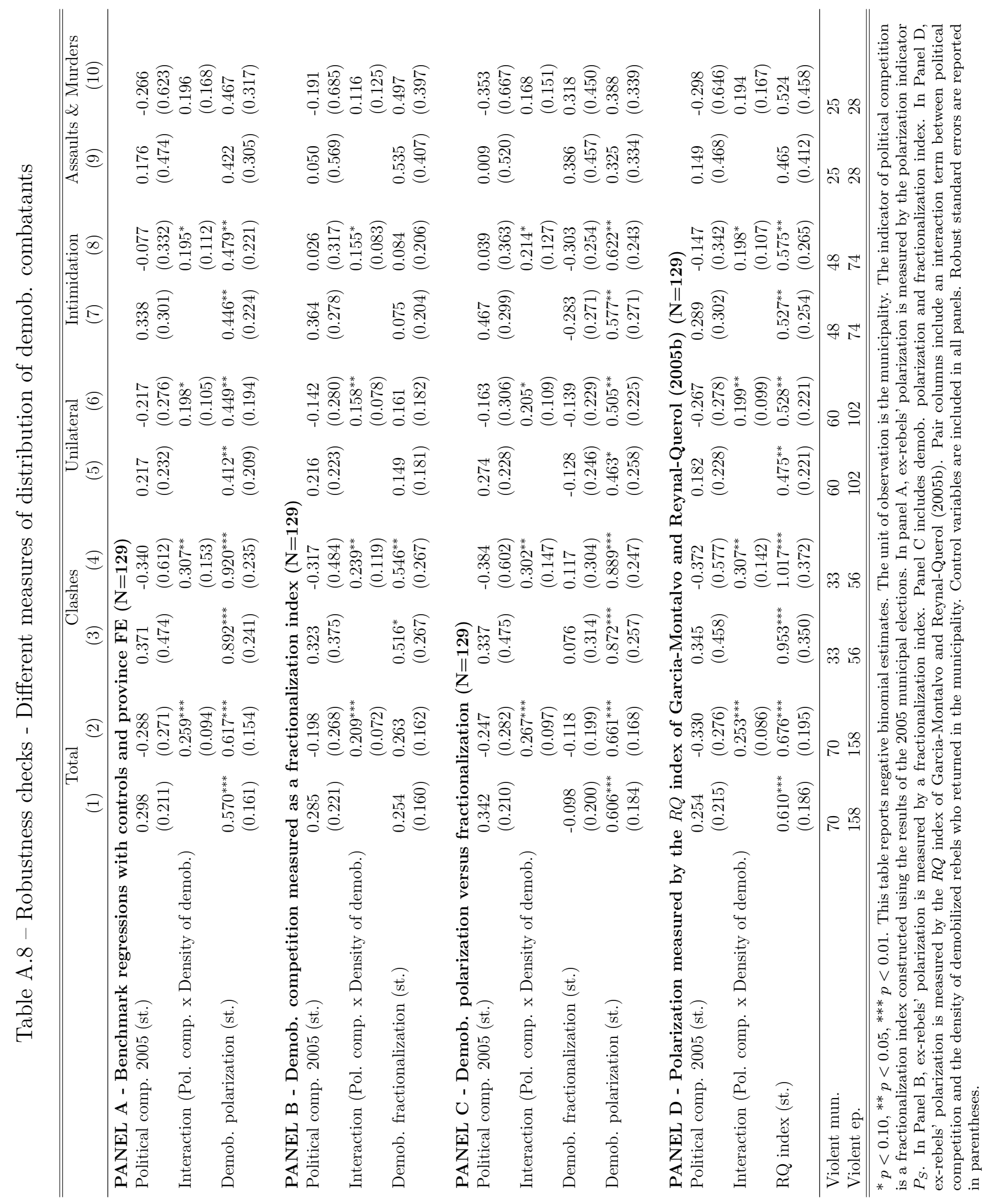




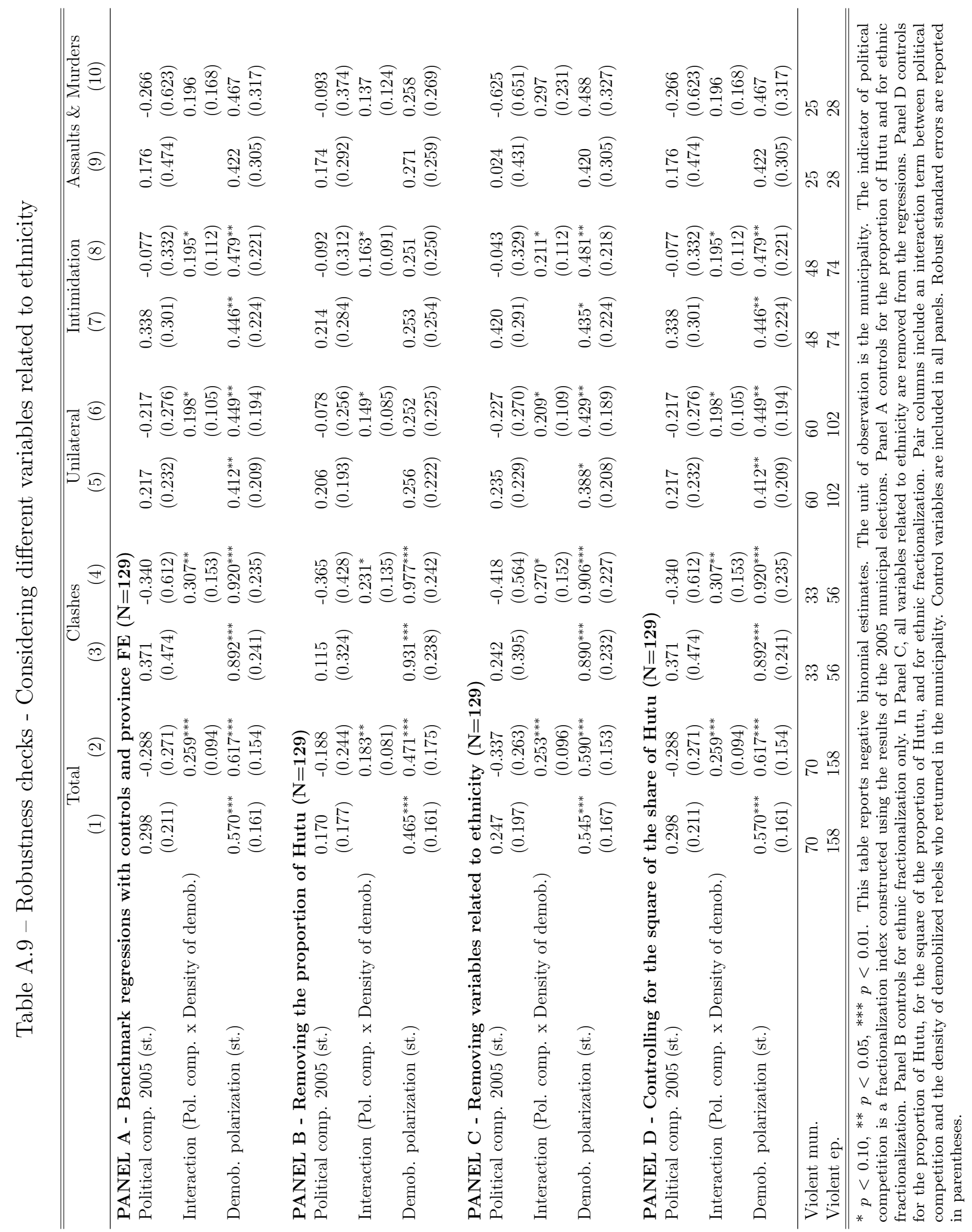




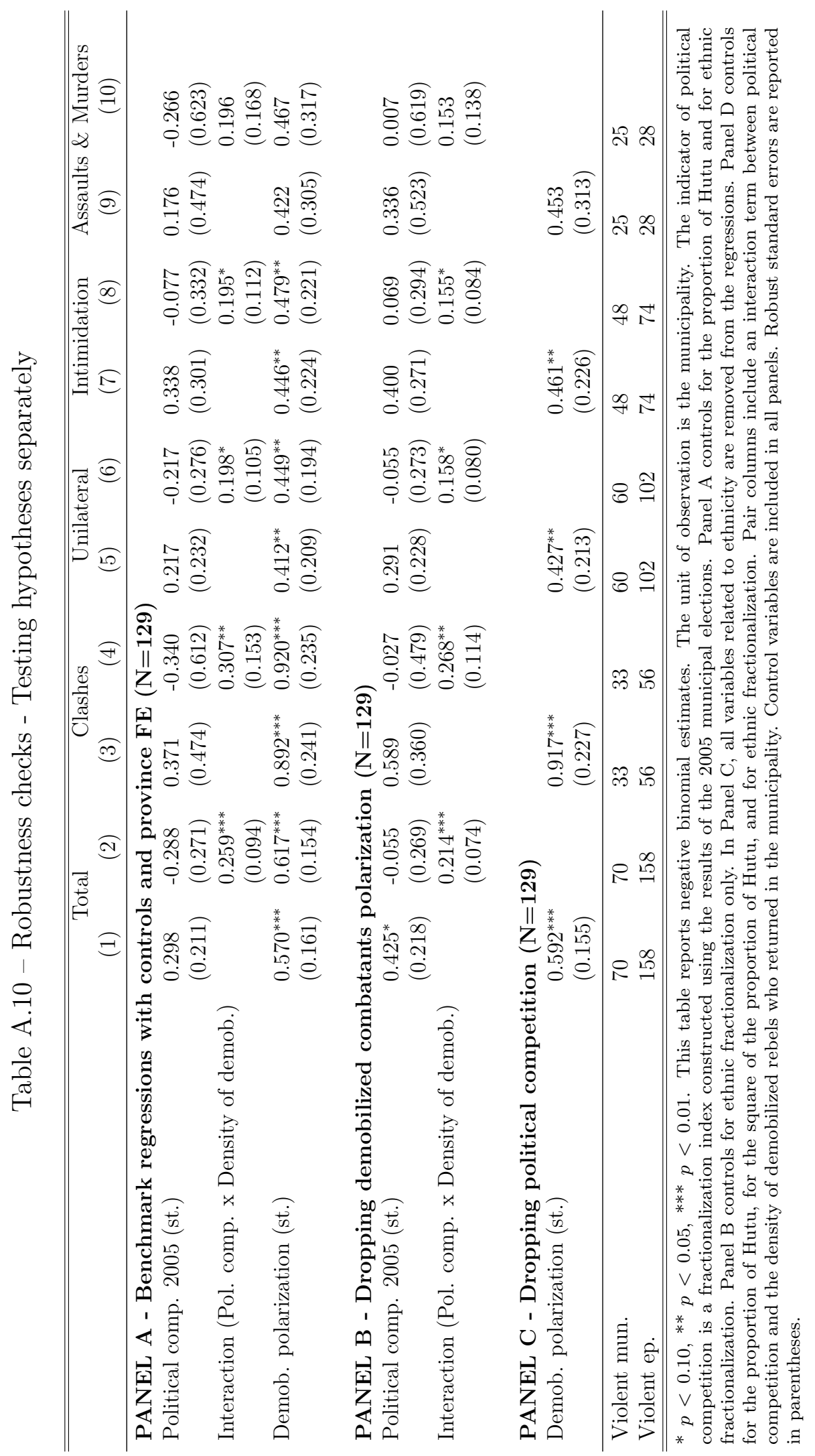




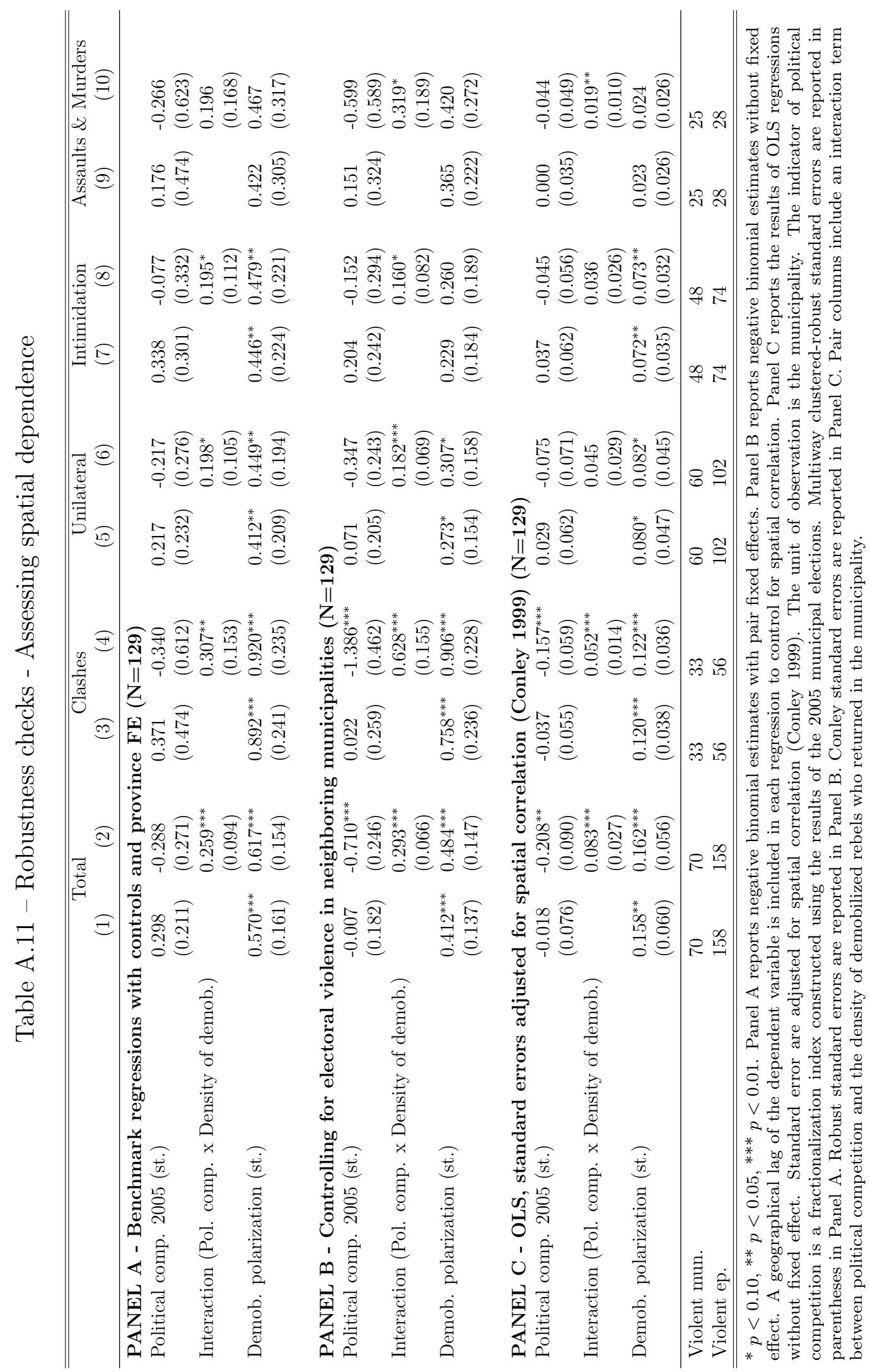




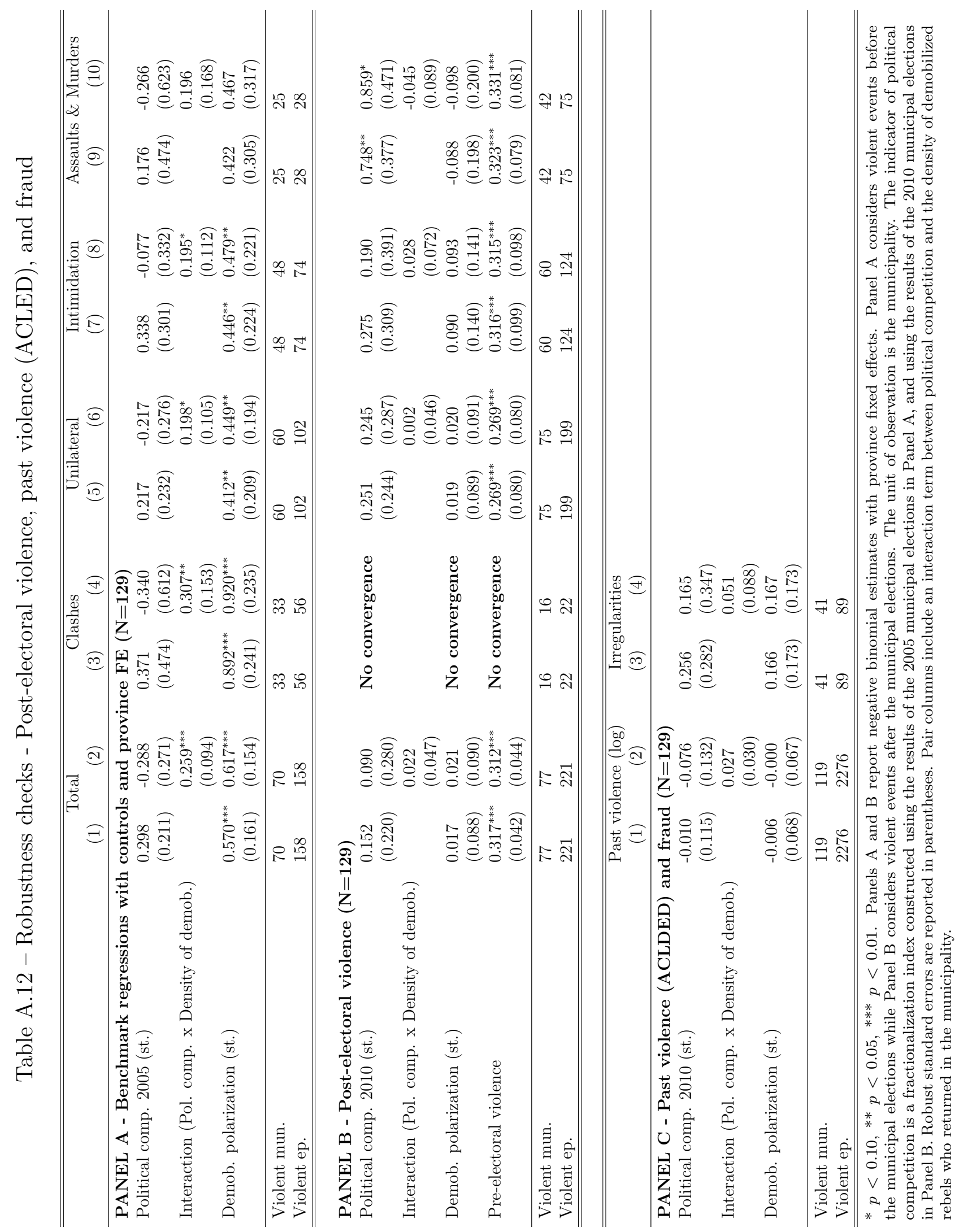


Table A.13 - Robustness of the interaction term between Political competition and the density of demobilized combatants

\begin{tabular}{|c|c|c|c|c|c|}
\hline & $\begin{array}{c}\text { Total } \\
(1)\end{array}$ & $\begin{array}{c}\text { Clashes } \\
(2)\end{array}$ & $\begin{array}{c}\text { Unilateral } \\
(3)\end{array}$ & $\begin{array}{c}\text { Intimidation } \\
\text { (4) }\end{array}$ & $\begin{array}{c}\text { Assaults } \\
\text { \& Murders } \\
(5)\end{array}$ \\
\hline \multicolumn{6}{|l|}{ PANEL A: Benchmark results } \\
\hline Political comp. 2005 (st.) & $\begin{array}{l}-0.288 \\
(0.271)\end{array}$ & $\begin{array}{l}-0.340 \\
(0.612)\end{array}$ & $\begin{array}{l}-0.217 \\
(0.276)\end{array}$ & $\begin{array}{l}-0.077 \\
(0.332)\end{array}$ & $\begin{array}{l}-0.266 \\
(0.623)\end{array}$ \\
\hline Interaction (Pol. comp. x Density of demob.) & $\begin{array}{l}0.259^{* * *} \\
(0.094)\end{array}$ & $\begin{array}{l}0.307^{* *} \\
(0.153)\end{array}$ & $\begin{array}{l}0.198^{*} \\
(0.105)\end{array}$ & $\begin{array}{l}0.195^{*} \\
(0.112)\end{array}$ & $\begin{array}{l}0.196 \\
(0.168)\end{array}$ \\
\hline Demob. polarization (st.) & $\begin{array}{l}0.617^{* * *} \\
(0.154)\end{array}$ & $\begin{array}{l}0.920^{* * *} \\
(0.235)\end{array}$ & $\begin{array}{l}0.449^{* *} \\
(0.194)\end{array}$ & $\begin{array}{l}0.479^{* *} \\
(0.221)\end{array}$ & $\begin{array}{l}0.467 \\
(0.317)\end{array}$ \\
\hline \multicolumn{6}{|c|}{ PANEL B: Extra interaction with precipitation } \\
\hline Political comp. 2005 (st.) & $\begin{array}{l}-1.287 \\
(2.471)\end{array}$ & $\begin{array}{l}-12.452^{\text {** }} \\
(6.333)\end{array}$ & $\begin{array}{l}1.575 \\
(2.742)\end{array}$ & $\begin{array}{l}1.081 \\
(3.021)\end{array}$ & $\begin{array}{l}3.495 \\
(5.580)\end{array}$ \\
\hline Interaction (Pol. comp. x Density of demob.) & $\begin{array}{l}0.284^{* * *} \\
(0.106)\end{array}$ & $\begin{array}{l}0.615^{* * *} \\
(0.199)\end{array}$ & $\begin{array}{l}0.159 \\
(0.101)\end{array}$ & $\begin{array}{l}0.167 \\
(0.117)\end{array}$ & $\begin{array}{l}0.137 \\
(0.170)\end{array}$ \\
\hline Demob. polarization (st.) & $\begin{array}{l}0.619^{* * *} \\
(0.155)\end{array}$ & $\begin{array}{l}1.026^{* * *} \\
(0.258)\end{array}$ & $\begin{array}{l}0.447^{* *} \\
(0.192)\end{array}$ & $\begin{array}{l}0.476^{* *} \\
(0.220)\end{array}$ & $\begin{array}{l}0.469 \\
(0.299)\end{array}$ \\
\hline Interaction (Pol. comp. x precipitation) & $\begin{array}{l}0.010 \\
(0.025)\end{array}$ & $\begin{array}{l}0.121^{*} \\
(0.065)\end{array}$ & $\begin{array}{l}-0.018 \\
(0.028)\end{array}$ & $\begin{array}{l}-0.011 \\
(0.030)\end{array}$ & $\begin{array}{l}-0.039 \\
(0.057)\end{array}$ \\
\hline \multicolumn{6}{|c|}{ PANEL C: Extra interaction with the "Tropical moist forest" dummy } \\
\hline Political comp. 2005 (st.) & $\begin{array}{l}-0.210 \\
(0.312)\end{array}$ & $\begin{array}{l}-0.069 \\
(0.539)\end{array}$ & $\begin{array}{l}-0.219 \\
(0.333)\end{array}$ & $\begin{array}{l}-0.043 \\
(0.382)\end{array}$ & $\begin{array}{l}-0.620 \\
(0.711)\end{array}$ \\
\hline Interaction (Pol. comp. x Density of demob.) & $\begin{array}{l}0.279^{* * *} \\
(0.098)\end{array}$ & $\begin{array}{l}0.416^{* *} \\
(0.166)\end{array}$ & $\begin{array}{l}0.197^{*} \\
(0.108)\end{array}$ & $\begin{array}{l}0.204^{*} \\
(0.117)\end{array}$ & $\begin{array}{l}0.150 \\
(0.188)\end{array}$ \\
\hline Demob. polarization (st.) & $\begin{array}{l}0.618^{* * *} \\
(0.154)\end{array}$ & $\begin{array}{l}0.953^{* * *} \\
(0.221)\end{array}$ & $\begin{array}{l}0.449^{* *} \\
(0.194)\end{array}$ & $\begin{array}{l}0.477^{* *} \\
(0.222)\end{array}$ & $\begin{array}{l}0.414 \\
(0.325)\end{array}$ \\
\hline Interaction (Pol. comp. x biome) & $\begin{array}{l}-0.287 \\
(0.432)\end{array}$ & $\begin{array}{c}-1.363^{*} \\
(0.812)\end{array}$ & $\begin{array}{l}0.006 \\
(0.492)\end{array}$ & $\begin{array}{l}-0.132 \\
(0.617)\end{array}$ & $\begin{array}{l}1.070 \\
(1.083)\end{array}$ \\
\hline \multicolumn{6}{|c|}{ PANEL D: Extra interaction with past violence } \\
\hline Political comp. 2005 (st.) & $\begin{array}{l}-0.179 \\
(0.407)\end{array}$ & $\begin{array}{l}-0.186 \\
(0.703)\end{array}$ & $\begin{array}{l}0.103 \\
(0.427)\end{array}$ & $\begin{array}{l}0.262 \\
(0.526)\end{array}$ & $\begin{array}{l}-0.445 \\
(0.751)\end{array}$ \\
\hline Interaction (Pol. comp. x Density of demob.) & $\begin{array}{l}0.266^{* * *} \\
(0.096)\end{array}$ & $\begin{array}{l}0.320^{* *} \\
(0.154)\end{array}$ & $\begin{array}{l}0.204^{*} \\
(0.106)\end{array}$ & $\begin{array}{l}0.203^{*} \\
(0.114)\end{array}$ & $\begin{array}{l}0.192 \\
(0.174)\end{array}$ \\
\hline Demob. polarization (st.) & $\begin{array}{l}0.631^{* * *} \\
(0.154)\end{array}$ & $\begin{array}{l}0.948^{* * *} \\
(0.232)\end{array}$ & $\begin{array}{l}0.479^{* *} \\
(0.197)\end{array}$ & $\begin{array}{l}0.510^{* *} \\
(0.217)\end{array}$ & $\begin{array}{l}0.440 \\
(0.314)\end{array}$ \\
\hline Interaction (Pol. comp. x past violence) & $\begin{array}{l}-0.048 \\
(0.121)\end{array}$ & $\begin{array}{l}-0.077 \\
(0.189)\end{array}$ & $\begin{array}{l}-0.125 \\
(0.114)\end{array}$ & $\begin{array}{l}-0.135 \\
(0.144)\end{array}$ & $\begin{array}{l}0.087 \\
(0.171)\end{array}$ \\
\hline \multicolumn{6}{|c|}{ PANEL E: Extra interaction with temperature } \\
\hline Political comp. 2005 (st.) & $\begin{array}{l}2.590 \\
(2.084)\end{array}$ & $\begin{array}{l}5.914^{*} \\
(3.549)\end{array}$ & $\begin{array}{l}5.594^{*} \\
(3.238)\end{array}$ & $\begin{array}{l}6.970^{* *} \\
(3.486)\end{array}$ & $\begin{array}{l}3.026 \\
(6.426)\end{array}$ \\
\hline Interaction (Pol. comp. x Density of demob.) & $\begin{array}{l}0.310^{* * *} \\
(0.103)\end{array}$ & $\begin{array}{l}0.405^{* *} \\
(0.176)\end{array}$ & $\begin{array}{l}0.289^{* *} \\
(0.117)\end{array}$ & $\begin{array}{l}0.317^{* *} \\
(0.132)\end{array}$ & $\begin{array}{l}0.234 \\
(0.169)\end{array}$ \\
\hline Demob. polarization (st.) & $\begin{array}{l}0.665^{* * *} \\
(0.153)\end{array}$ & $\begin{array}{l}1.020^{* * *} \\
(0.236)\end{array}$ & $\begin{array}{l}0.563^{* * *} \\
(0.203)\end{array}$ & $\begin{array}{l}0.642^{* * *} \\
(0.234)\end{array}$ & $\begin{array}{l}0.518 \\
(0.332)\end{array}$ \\
\hline Interaction (Pol. comp. x temperature) & $\begin{array}{l}-0.145 \\
(0.103)\end{array}$ & $\begin{array}{c}-0.314^{*} \\
(0.176)\end{array}$ & $\begin{array}{c}-0.295^{*} \\
(0.160)\end{array}$ & $\begin{array}{l}-0.362^{* *} \\
(0.175)\end{array}$ & $\begin{array}{l}-0.164 \\
(0.312)\end{array}$ \\
\hline \multicolumn{6}{|c|}{ PANEL F: Extra interaction with the 2005 results of Uprona } \\
\hline Political comp. 2005 (st.) & $\begin{array}{l}-0.360 \\
(0.281)\end{array}$ & $\begin{array}{l}-0.452 \\
(0.603)\end{array}$ & $\begin{array}{l}-0.300 \\
(0.281)\end{array}$ & $\begin{array}{l}-0.093 \\
(0.341)\end{array}$ & $\begin{array}{c}-0.542 \\
(0.637)\end{array}$ \\
\hline Interaction (Pol. comp. x Density of demob.) & $\begin{array}{l}0.267^{* * *} \\
(0.097)\end{array}$ & $\begin{array}{l}0.317^{* *} \\
(0.157)\end{array}$ & $\begin{array}{l}0.207^{*} \\
(0.108)\end{array}$ & $\begin{array}{l}0.197^{*} \\
(0.115)\end{array}$ & $\begin{array}{l}0.201 \\
(0.162)\end{array}$ \\
\hline Demob. polarization (st.) & $\begin{array}{l}0.644^{* * *} \\
(0.173)\end{array}$ & $\begin{array}{l}0.979^{* * *} \\
(0.257)\end{array}$ & $\begin{array}{l}0.483^{* *} \\
(0.216)\end{array}$ & $\begin{array}{l}0.484^{* *} \\
(0.240)\end{array}$ & $\begin{array}{l}0.612^{* *} \\
(0.306)\end{array}$ \\
\hline Interaction (Pol. comp. x UPRONA ) & $\begin{array}{l}1.746 \\
(2.380)\end{array}$ & $\begin{array}{l}2.965 \\
(3.818)\end{array}$ & $\begin{array}{l}2.146 \\
(2.772)\end{array}$ & $\begin{array}{l}0.413 \\
(3.473)\end{array}$ & $\begin{array}{l}7.292 \\
(5.738)\end{array}$ \\
\hline Violent mun. & 79 & 33 & 60 & 48 & 25 \\
\hline Violent ep. & 158 & 56 & 102 & 74 & 28 \\
\hline
\end{tabular}

${ }^{*} p<0.10, * * p<0.05, * * * p<0.01$. This table reports negative binomial estimates. The unit of observation is the municipality. The indicator of political competition is a fractionalization index constructed using the results of the 2005 municipal elections. Control variables are included in all panels. Robust standard errors are reported in parentheses. 
Table A.14 - Triple interaction between Political competition, the density of demobilized combatants, and ex-rebels polarization

\begin{tabular}{|c|c|c|c|c|c|}
\hline & $\begin{array}{l}\text { Total } \\
(1)\end{array}$ & $\begin{array}{c}\text { Clashes } \\
(2)\end{array}$ & $\begin{array}{c}\text { Unilateral } \\
(3)\end{array}$ & $\begin{array}{c}\text { Intimidation } \\
\text { (4) }\end{array}$ & $\begin{array}{c}\text { Assaults } \\
\text { \& Murders } \\
(5)\end{array}$ \\
\hline \multicolumn{6}{|l|}{ PANEL A: Benchmark results } \\
\hline Political comp. 2005 (st.) & $\begin{array}{l}-0.288 \\
(0.271)\end{array}$ & $\begin{array}{l}-0.340 \\
(0.612)\end{array}$ & $\begin{array}{l}-0.217 \\
(0.276)\end{array}$ & $\begin{array}{l}-0.077 \\
(0.332)\end{array}$ & $\begin{array}{l}-0.266 \\
(0.623)\end{array}$ \\
\hline Interaction (Pol. comp. x Density of demob.) & $\begin{array}{l}0.259^{* * *} \\
(0.094)\end{array}$ & $\begin{array}{l}0.307^{* *} \\
(0.153)\end{array}$ & $\begin{array}{l}0.198^{*} \\
(0.105)\end{array}$ & $\begin{array}{l}0.195^{*} \\
(0.112)\end{array}$ & $\begin{array}{l}0.196 \\
(0.168)\end{array}$ \\
\hline Demob. polarization (st.) & $\begin{array}{l}0.617^{* * *} \\
(0.154)\end{array}$ & $\begin{array}{l}0.920^{* * *} \\
(0.235)\end{array}$ & $\begin{array}{l}0.449^{* *} \\
(0.194)\end{array}$ & $\begin{array}{l}0.479^{* *} \\
(0.221)\end{array}$ & $\begin{array}{l}0.467 \\
(0.317)\end{array}$ \\
\hline \multicolumn{6}{|l|}{ PANEL B: Triple interaction term } \\
\hline Political comp. 2005 (st.) & $\begin{array}{l}-0.206 \\
(0.281)\end{array}$ & $\begin{array}{l}-0.354 \\
(0.717)\end{array}$ & $\begin{array}{l}-0.172 \\
(0.272)\end{array}$ & $\begin{array}{l}-0.034 \\
(0.385)\end{array}$ & $\begin{array}{c}-0.371 \\
(0.643)\end{array}$ \\
\hline Demob. polarization (st.) & $\begin{array}{l}0.440 \\
(0.268)\end{array}$ & $\begin{array}{l}0.706 \\
(0.433)\end{array}$ & $\begin{array}{l}0.332 \\
(0.267)\end{array}$ & $\begin{array}{l}0.173 \\
(0.295)\end{array}$ & $\begin{array}{l}1.035^{* *} \\
(0.422)\end{array}$ \\
\hline Density of demob. (/1000) & $\begin{array}{l}0.084 \\
(0.109)\end{array}$ & $\begin{array}{l}0.292^{*} \\
(0.174)\end{array}$ & $\begin{array}{c}-0.034 \\
(0.119)\end{array}$ & $\begin{array}{c}-0.114 \\
(0.139)\end{array}$ & $\begin{array}{l}0.094 \\
(0.179)\end{array}$ \\
\hline Pol. comp. x Density of demob. & $\begin{array}{l}0.236^{* * *} \\
(0.091)\end{array}$ & $\begin{array}{l}0.374^{*} \\
(0.196)\end{array}$ & $\begin{array}{l}0.182^{*} \\
(0.094)\end{array}$ & $\begin{array}{l}0.220 \\
(0.149)\end{array}$ & $\begin{array}{l}0.241^{*} \\
(0.134)\end{array}$ \\
\hline Pol. comp. x Demob pol. & $\begin{array}{l}-0.055 \\
(0.252)\end{array}$ & $\begin{array}{l}0.276 \\
(0.521)\end{array}$ & $\begin{array}{l}-0.091 \\
(0.289)\end{array}$ & $\begin{array}{l}0.089 \\
(0.352)\end{array}$ & $\begin{array}{l}-0.564 \\
(0.623)\end{array}$ \\
\hline Density of demob. x Demob pol. & $\begin{array}{l}0.032 \\
(0.090)\end{array}$ & $\begin{array}{l}0.071 \\
(0.138)\end{array}$ & $\begin{array}{l}0.024 \\
(0.103)\end{array}$ & $\begin{array}{l}0.111 \\
(0.117)\end{array}$ & $\begin{array}{l}-0.251 \\
(0.154)\end{array}$ \\
\hline Pol. comp. x Density of demob. x Demob pol. & $\begin{array}{l}-0.154 \\
(0.148)\end{array}$ & $\begin{array}{l}-0.242 \\
(0.231)\end{array}$ & $\begin{array}{l}-0.110 \\
(0.177)\end{array}$ & $\begin{array}{l}-0.306 \\
(0.231)\end{array}$ & $\begin{array}{l}0.281 \\
(0.381)\end{array}$ \\
\hline Violent mun. & 79 & 33 & 60 & 48 & 25 \\
\hline Violent ep. & 158 & 56 & 102 & 74 & 28 \\
\hline
\end{tabular}

$* p<0.10,{ }^{* *} p<0.05$, *** $p<0.01$. This table reports negative binomial estimates. The unit of observation is the municipality. The indicator of political competition is a fractionalization index constructed using the results of the 2005 municipal elections. Control variables are included in all panels. Robust standard errors are reported in parentheses. 


\section{E Appendix - Figures}
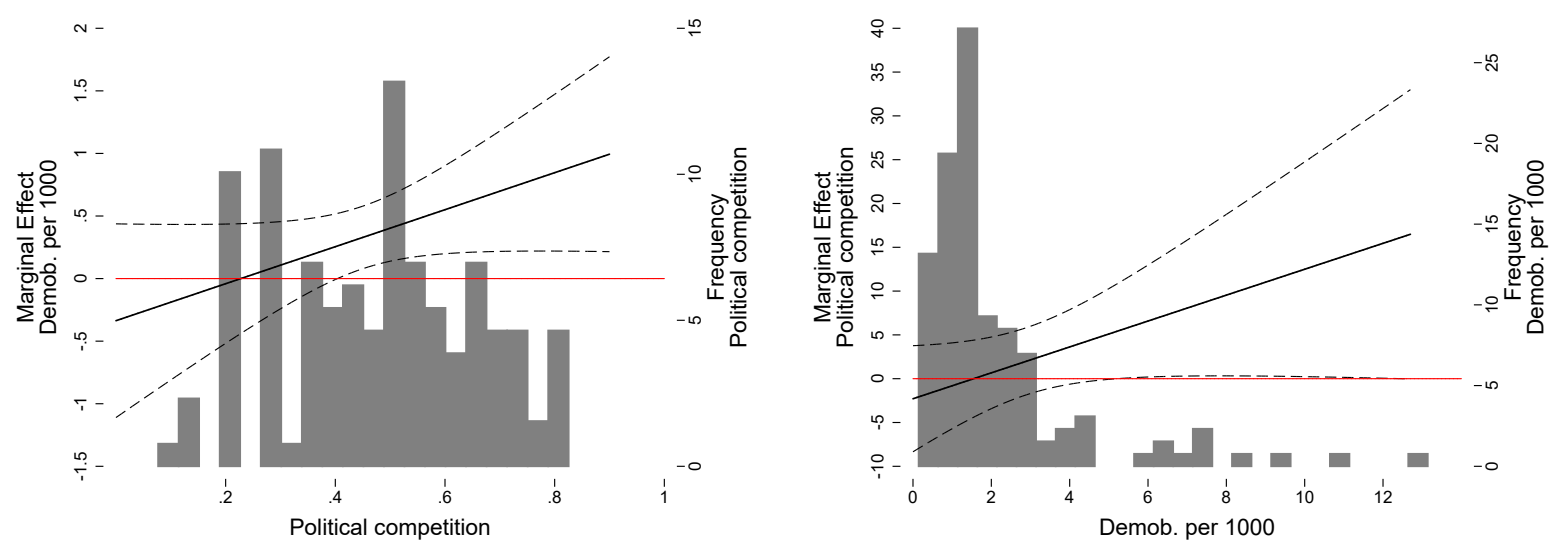

(a) Marginal effect of the number of demobilized as a(b) Marginal effect of political competition as a funcfunction of political competition (95\% CI) tion the number of demobilized (95\% CI)

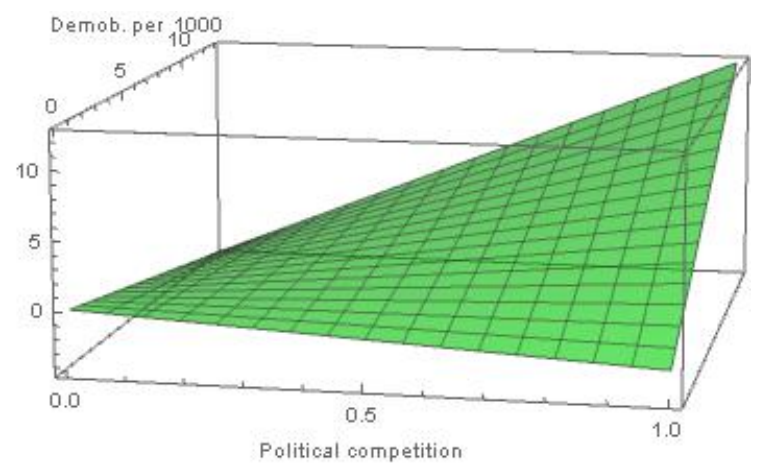

(c) Joint predicted effect of political competition and number of demobilized rebels

Figure 8 - Clashes - interpretation of the interaction term (based on Table 7, Panel D, column (4)) 

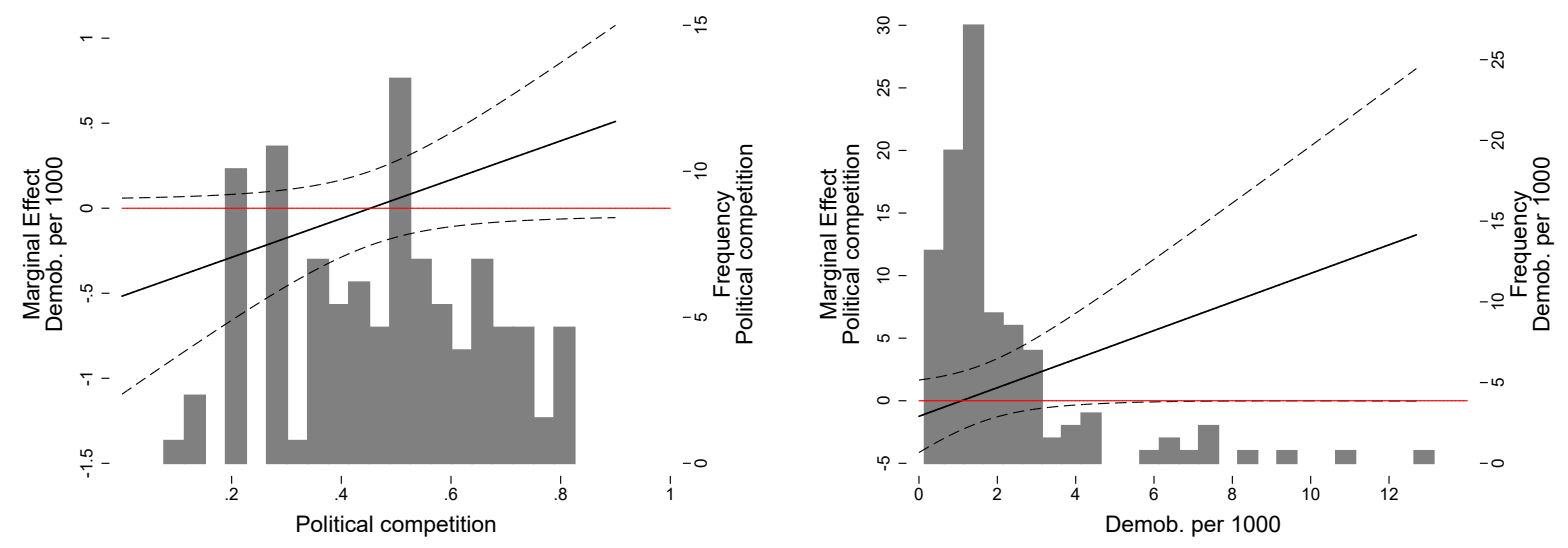

(a) Marginal effect of the number of demobilized as a(b) Marginal effect of political competition as a funcfunction of political competition (95\% CI) tion the number of demobilized (95\% CI)

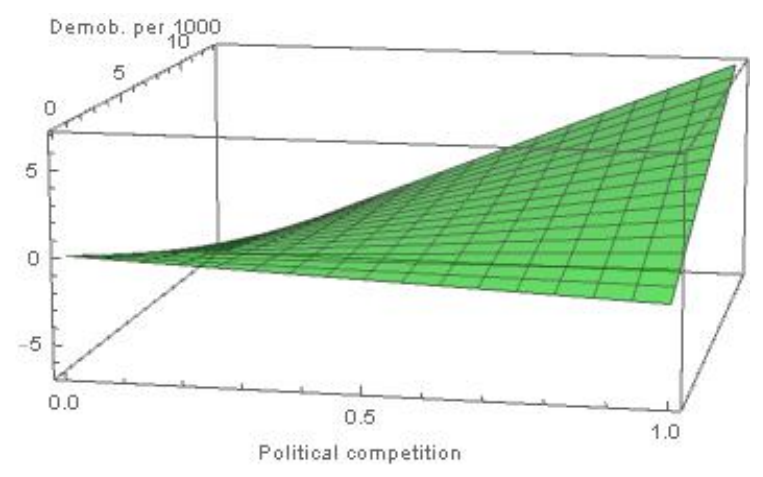

(c) Joint predicted effect of political competition and number of demobilized rebels

Figure 9 - Unilateral violence - interpretation of the interaction term (based on Table 7, Panel D, column (6)) 

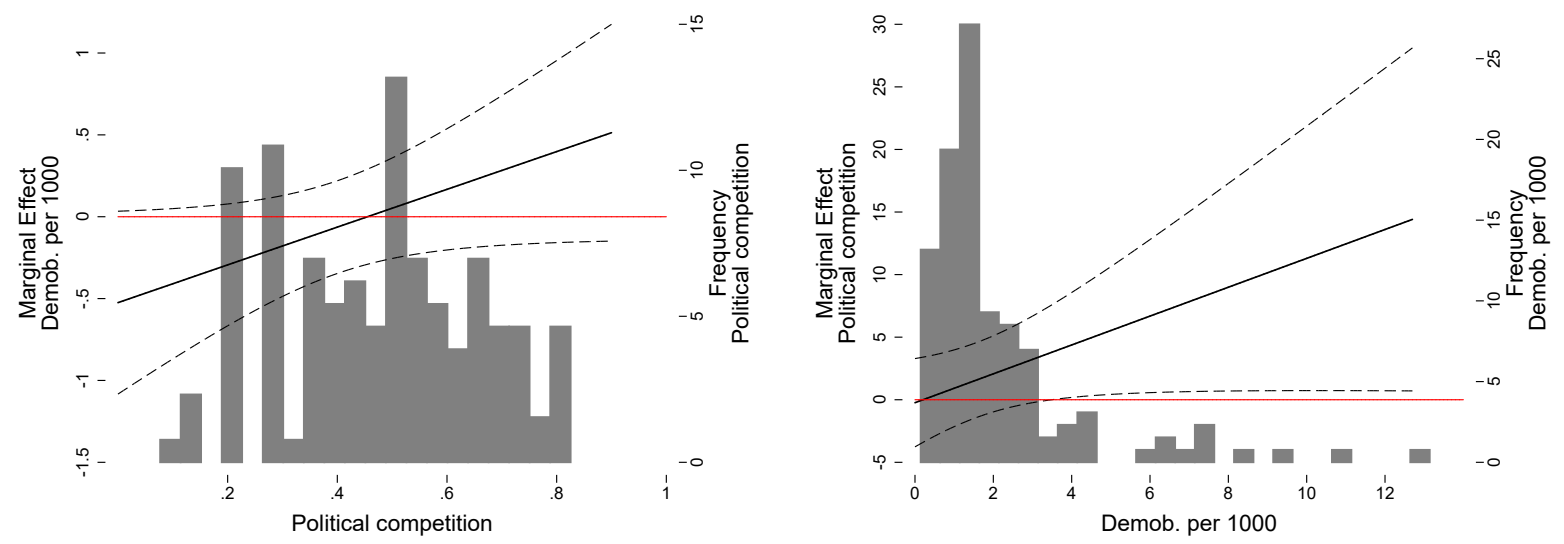

(a) Marginal effect of the number of demobilized as a(b) Marginal effect of political competition as a funcfunction of political competition (95\% CI) tion the number of demobilized (95\% CI)

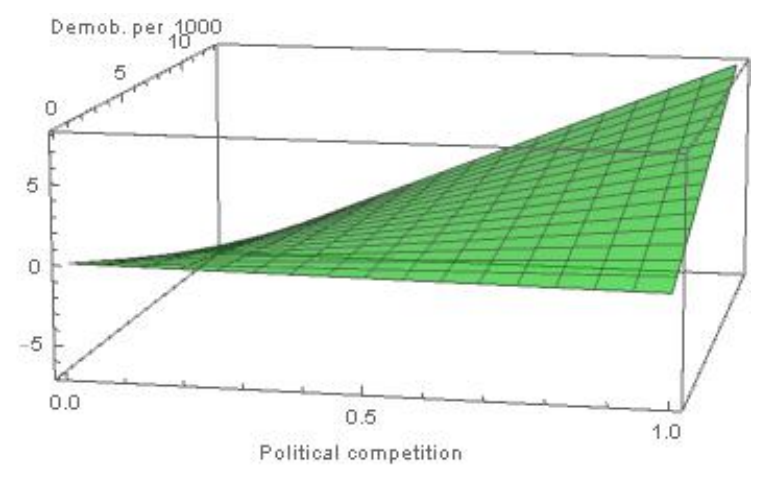

(c) Joint predicted effect of political competition and number of demobilized rebels

Figure 10 - Acts of intimidation - interpretation of the interaction term (based on Table 7, Panel D, column (8)) 

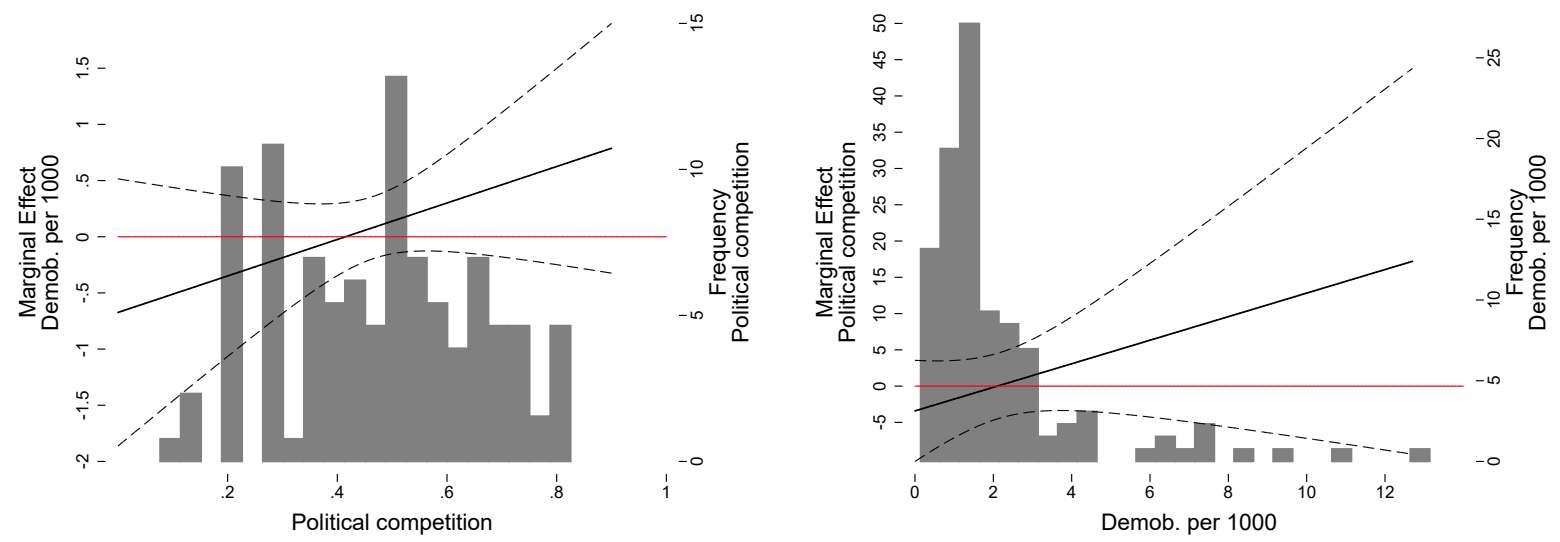

(a) Marginal effect of the number of demobilized as a(b) Marginal effect of political competition as a funcfunction of political competition (95\% CI) tion the number of demobilized $(95 \% \mathrm{CI})$

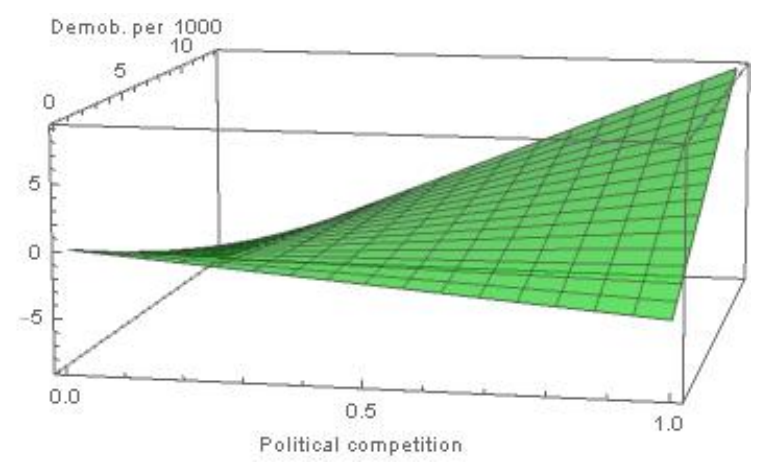

(c) Joint predicted effect of political competition and number of demobilized rebels

Figure 11 - Assaults and murders - interpretation of the interaction term (based on Table 7, Panel D, column (10)) 